\title{
Review Article \\ Inflammation, Vasospasm, and Brain Injury after Subarachnoid Hemorrhage
}

\author{
Brandon A. Miller, ${ }^{1}$ Nefize Turan, ${ }^{1}$ Monica Chau, ${ }^{2}$ and Gustavo Pradilla ${ }^{1,3}$ \\ ${ }^{1}$ Department of Neurological Surgery, Emory University School of Medicine, Atlanta, GA, USA \\ ${ }^{2}$ Division of Neuropathology, Department of Pathology, Emory University School of Medicine, Atlanta, GA, USA \\ ${ }^{3}$ Cerebrovascular Research Laboratory, Grady Memorial Hospital, Emory University School of Medicine, 1365 Clifton Road, \\ NE, Suite B6166, Atlanta, GA, USA \\ Correspondence should be addressed to Gustavo Pradilla; gpradil@emory.edu
}

Received 14 February 2014; Revised 14 May 2014; Accepted 26 May 2014; Published 3 July 2014

Academic Editor: Aaron S. Dumont

Copyright (C) 2014 Brandon A. Miller et al. This is an open access article distributed under the Creative Commons Attribution License, which permits unrestricted use, distribution, and reproduction in any medium, provided the original work is properly cited.

\begin{abstract}
Subarachnoid hemorrhage (SAH) can lead to devastating neurological outcomes, and there are few pharmacologic treatments available for treating this condition. Both animal and human studies provide evidence of inflammation being a driving force behind the pathology of SAH, leading to both direct brain injury and vasospasm, which in turn leads to ischemic brain injury. Several inflammatory mediators that are elevated after SAH have been studied in detail. While there is promising data indicating that blocking these factors might benefit patients after SAH, there has been little success in clinical trials. One of the key factors that complicates clinical trials of SAH is the variability of the initial injury and subsequent inflammatory response. It is likely that both genetic and environmental factors contribute to the variability of patients' post-SAH inflammatory response and that this confounds trials of anti-inflammatory therapies. Additionally, systemic inflammation from other conditions that affect patients with SAH could contribute to brain injury and vasospasm after SAH. Continuing work on biomarkers of inflammation after SAH may lead to development of patient-specific anti-inflammatory therapies to improve outcome after SAH.
\end{abstract}

\section{Introduction}

Subarachnoid hemorrhage (SAH) remains a devastating disease, leaving survivors with neurological injuries that range from subtle cognitive deficits to disabling cerebral infarctions. While treatment continues to evolve and improve, there are few therapies that treat the underlying pathological mechanisms of SAH. Additionally, there is no clear explanation for the heterogeneity among patients with $\mathrm{SAH}$, with some recovering well and others worsening after their initial ictus. In this review, we will discuss the evidence supporting the role of inflammation as a direct mediator of neurological injury after SAH and a causative factor of post-SAH vasospasm. We hypothesize that the diffuse inflammatory response after SAH results in acute and chronic neurological injury and vasospasm and that patients with more severe inflammatory responses may experience worse outcomes after SAH. An improved understanding of the inflammatory pathways activated after SAH will likely lead to novel therapies and improved patient outcomes.

\section{Evidence for Acute Inflammation after Subarachnoid Hemorrhage}

2.1. Detection of Inflammatory Mediators in CSF after SAH. Several human studies have repeatedly shown elevated inflammatory mediators within CSF after SAH. While the key mediators identified may vary across studies, the relationship between elevation, onset of vasospasm, and decreased neurological outcomes remains a consistent finding $[1,2]$. A study by Polin and colleagues [3] showed that patients who developed vasospasm after SAH had higher CSF levels of Eselectin, an endothelial cell molecule that induces leukocyte adherence and extravasation and subsequent tissue injury in ischemic stroke [4-6]. These findings are supported by 
experimental data showing that CSF from patients with SAH increased rolling and adhesion of leukocytes in an in vitro mouse model [7]. While there are other studies showing elevation of E-selectin after SAH [8], some have failed to detect E-selectin in the CSF of patients with SAH, even when other inflammatory molecules, such as monocyte chemoattractant protein-1 (MCP-1), were elevated [9]. Other cytokines that have been widely cited to play a role in $\mathrm{SAH}$, such as tumor necrosis factor-alpha (TNF $\alpha)$, also show wide variation in expression when compared across different studies. For instance, Kikuchi and colleagues found elevated levels of interleukin- (IL-) 6 and IL- 8 but not TNF $\alpha$ after $\mathrm{SAH}$, while other groups have found elevations of TNF $\alpha$ in the CSF after SAH $[2,10,11]$. One recent study found detectable levels of TNF $\alpha$ in only $30 \%$ of patients after $\mathrm{SAH}$, indicating that the inflammatory response after $\mathrm{SAH}$ may be quite heterogeneous [12]. The differences across these studies may be the result of different CSF collection times after SAH, alternative methods of detection used, or diverse patient populations. In addition, cross contamination of CSF with blood during collection from ventricular or lumbar sources is rarely accounted for. The volume of blood present within the subarachnoid space would obviously affect the levels of cytokines present in CSF, and therefore cytokine concentration in CSF may reflect the volume of SAH rather than the magnitude of the inflammatory response within the brain.

One of the most widely studied molecules in SAH is endothelin-1 (ET-1), a vasoconstrictor produced by endothelial cells. ET-1 has been detected in CSF from patients with $\mathrm{SAH}$ and can be produced by monocytes isolated from CSF of SAH patients $[13,14]$. ET-1 has been implicated in the development of vasospasm after SAH [15] and will be discussed in detail later in this review. As with many other proinflammatory molecules, the expression of ET-1 is highly variable: in a study by Fassbender and colleagues, ET-1 was not found in CSF of control subjects, and only $46 \%$ of patients with SAH had detectable levels of ET-1 [13]. Though the averaged results of both groups revealed a significant increase in ET-1 after SAH, this demonstrates that not all patients with SAH experience the same inflammatory response. Furthermore, a study from a different group failed to detect ET-1 after SAH [16]. This heterogeneity is readily apparent to clinicians treating $\mathrm{SAH}$, as many patients move through their posthemorrhage course with few complications, while others experience severe complications such as vasospasm and cerebral edema, which may both be driven by an inflammatory response $[17,18]$.

2.2. Detection of Inflammatory Mediators in Blood after SAH. In addition to the inflammatory cytokines found within CSF in patients after $\mathrm{SAH}$, a systemic increase in inflammatory mediators after SAH is well documented $[1,19,20]$. This systemic increase in inflammatory cytokines after SAH is predictive of poor outcome and may be related to a late, rather than early, inflammatory response [21-24]. Other markers of systemic inflammation, such as high body temperature and leukocytosis, have also correlated with worse outcomes after SAH; however, no causal relationship was established between peripheral inflammation and intracerebral pathology $[25,26]$. There is increasing interest in developing inflammatory biomarkers for prognosticating outcome in $\mathrm{SAH}$ though no biomarker study in SAH has been prospectively validated [27]. It is unclear to what extent the presence of inflammatory cytokines in plasma is due to intracerebral processes or how strongly blood cytokine levels correlate with inflammation within the brain [12]. It is quite possible that inflammatory cytokines detected in plasma are indicators of global inflammation throughout the body, as would be expected in patients who are critically ill after SAH. For example, both ICAM-1 and E-selectin have been used to prognosticate outcome in critically ill patients without $\mathrm{SAH}$ [28]. It is also possible that inflammatory cytokines within the blood contribute to brain injury after SAH; the breakdown of the blood brain barrier after SAH could allow serum cytokines to enter the brain parenchyma leading to tissue injury there.

In planning any trial of anti-inflammatory therapy after $\mathrm{SAH}$, consideration should be given to when the peak of inflammation occurs, in order to optimize delivery and dosing of the therapy. There is evidence that the expression of certain inflammatory molecules peaks within 24 hours after hemorrhage onset, with IL- 6 being elevated at days 0 to 1 after SAH [29] though others have shown a peak of IL-6 at day 6 after SAH [30]. Once again, differences between these two studies may be due to many factors, including the high degree of variability among inflammatory responses among patients with SAH $[3,10]$.

\subsection{Inflammation and Aneurysm Formation. Inflammation} may also play a role in aneurysm formation. Several previously discussed inflammatory cytokines, such as TNF $\alpha$ and MCP-1, are thought to play a role in endothelial injury and remodeling based on evidence from both human and animal studies [31, 32]. A recent clinical study found increased cyclooxygenase within the walls of ruptured and unruptured aneurysms [33] and the same group has shown that aspirin may reduce the rate of aneurysm rupture due to its antiinflammatory properties $[34,35]$. E-selectin has also been found at elevated levels in the walls of aneurysms [36]. Additionally, environmental factors that contribute to a proinflammatory state may contribute to aneurysm formation [37]. A detailed discussion of the contribution of inflammation to aneurysm formation is outside the scope of this review and was reviewed recently elsewhere [38].

\section{Evidence for Inflammation in Animal Models of SAH}

Animal models have been utilized to establish a causative relationship between inflammation and brain injury after SAH. Several animal models for SAH exist, each with their own advantages and drawbacks [39]. Common models include blood injection into the basal cisterns of animals or endovascular perforation, both of which produce vasospasm and an inflammatory response [40-42]. As in human SAH 
studies, there is considerable variability between subjects when inflammatory responses are quantified $[43,44]$. Animal studies of SAH have found evidence of inflammation in all intracerebral compartments: CSF, brain parenchyma, and vasculature [45-49].

Animal studies have been used to link inflammation, cerebral edema, and cell death after SAH. The anesthetic isoflurane has been shown to reduce TNF $\alpha$ production, leukocyte adhesion molecule expression, and blood brain barrier permeability after experimental SAH $[50,51]$. The results of these studies are promising but do not prove whether decreased TNF $\alpha$ levels in affected tissue are a cause or result of decreased leukocyte infiltration. There is, however, evidence of TNF $\alpha$ having a direct role on neuronal injury after SAH. Recently, blockade of TNF $\alpha$ was shown to reduce apoptosis in the hippocampus after SAH [52]. This corresponds well to the extensive literature demonstrating a role for TNF $\alpha$ in neuronal apoptosis in other forms of neurological injury [53]. However, the antiapoptotic effects of TNF $\alpha$ blockade were not uniform throughout the brain, and a pre-rather than posttreatment paradigm was utilized in this study [52]. Furthermore, there is not even a consensus that neuronal death occurs in SAH, with some groups reporting no neuronal apoptosis after SAH while others observe neuronal death throughout the brain after SAH [5456]. Regardless of whether or not neuronal death occurs after $\mathrm{SAH}$, there are other pathological events that could explain neurological dysfunction after SAH, such as synaptic injury, loss of long term potentiation, and white matter injury [57]. Both synaptic loss and white matter injury are mediated by inflammation in models of other neurological diseases; however, more work is needed to understand the precise role of inflammation on cell death and injury after SAH $[58,59]$.

Animal models of SAH have also found evidence for inflammation playing a role in injury outside of the brain. In a study using endovascular perforation as a model of SAH in rats, systemic anti-inflammatory treatment was able to reduce lung injury after SAH [60]. This is relevant to SAH treatment as many patients experience cardiopulmonary complications as part of a systemic reaction to SAH [61]. Animal models of SAH have played an essential role in linking inflammation to vasospasm after $\mathrm{SAH}$ and will be discussed in more detail below.

\section{The Role of Inflammation in Vasospasm after SAH}

4.1. Induction of Vasospasm with Proinflammatory Agents. Early clinical studies showing a correlation between vasospasm and fever in the absence of infection established a link between inflammation and vasospasm [77-86]. Several proinflammatory agents such as talc (crystallized hydrous magnesium sulfate) $[87,88]$, latex, polystyrene, and dextran beads [89, 90], lipopolysaccharide (LPS) [91], and tenascin-C [92] have been administered intracisternally to show that vasospasm can occur in the absence of blood. These studies provided proof that vasospasm is not dependent on red blood cells (RBCs) or hemoglobin (Hgb) and confirmed the role of inflammation in the development of vasospasm.
4.2. Inflammatory Molecules Linked to Development of Vasospasm. Among inflammatory molecules linked to cerebral vasospasm, the selectin family, which consists of three members: E-selectin, platelet- (P-) selectin, and leukocyte(L-) selectin, has been extensively studied. These molecules facilitate leukocyte binding and migration through vascular endothelium towards injured tissue. L-selectin and Eselectin are constitutively expressed on cell surfaces whereas P-selectin expression requires activation by histamine or thrombin [93]. E-selectin is elevated in the CSF of SAH patients with higher concentrations seen in patients who develop moderate or severe vasospasm [3]. Inhibition of E-selectin with an inhibitory antibody [62] and E-selectin tolerization via intranasal administration have decreased vasospasm in rodent SAH models [63]. However, not all data point to selectins having deleterious effects after SAH: while P-selectin levels were higher in patients with SAH who developed cerebral ischemia after SAH, L-selectins were higher in patients who did not develop delayed ischemia $[23,94]$.

Integrins are cell surface proteins that facilitate cell-cell adhesion and interaction. The main integrins involved in leukocyte adhesion and migration are lymphocyte function-associated antigen 1 (LFA-1) and Mac-1 integrin (CD11b/CD18). Systemically administered anti-LFA-1 and Mac-1 monoclonal antibodies reduce vasospasm in rat [64], rabbit [65], and primate [66] SAH models. Immunoglobulin superfamily proteins, such as ICAM-1, play a role in leukocyte adhesion and are upregulated in patients who develop clinical vasospasm [3] as well as in rabbit [70] and canine SAH models [47]. Anti-ICAM-1 monoclonal antibodies were shown to decrease femoral artery vasospasm and inhibit infiltration of macrophages and neutrophils into blood vessel adventitia in a rodent model [95] and reduce vasospasm in a rabbit model of SAH [71].

Key proinflammatory cytokines elevated in experimental models and patients with vasospasm include IL-1B, IL-6, IL8 , TNF $\alpha$, and MCP-1. IL- 6 has been shown to peak early after $\mathrm{SAH}$, suggesting that it may be an early marker for predicting vasospasm development $[9,11,47,96-101]$. TNF $\alpha$ levels in poor-grade SAH patients were shown to correlate with severity of vasospasm [68] and serum MCP-1 levels were associated with predicting negative outcome but not severity of vasospasm [21]. Cytokine inhibitor CNI-1493 [72], antiIL-6 antibodies [102], anti-IL-1B antibodies [67], and TNF $\alpha$ inhibitors [103] have all been shown to attenuate vasospasm in animal models.

Several studies have examined intracellular signaling pathways activated during inflammation and their role in vasospasm. Mitogen-activated protein-kinase (MAPK) and nuclear factor kappa-B $(\mathrm{Nf} \kappa \mathrm{B})$ intracellular signaling pathways are crucial in generating inflammatory immune responses [104]. Jun N-terminal kinase 1 (JNK1) and JNK2, which are part of MAPK family, are activated in the cerebral vasculature after experimental SAH and their inhibition reduces vasospasm $[105,106]$. Inhibition of JNK was also effective at reversing the vasoconstrictive effects of tenascin$\mathrm{C}$ in a rat model of SAH [92]. Poly (ADP-ribose) polymerase (PARP) is a nuclear enzyme that regulates adhesion molecule 
expression and neutrophil recruitment during inflammation [107]. In a rabbit model of SAH, Satoh and colleagues showed PARP activation within the smooth muscle and adventitia of blood-exposed vessels and that PARP inhibition decreased the severity of vasospasm [108].

The complement pathway of antibacterial proteins also affects vasospasm after SAH. Complement depletion by treatment with cobra venom [109] and prevention of complement activation with nafamostat mesilate, a serine protease inhibitor, reduced vasospasm in experimental models [90, $110]$ and human subjects [111, 112]. Moreover, expression of the membrane attack complex (MAC) is increased in a rat model of SAH and can be responsible for lysis of extravasated erythrocytes and release of hemoglobin after SAH [113]. Recently, the lectin complement pathway (LCP) has also shown to be activated after SAH, and LCP activity has been linked to SAH severity and vasospasm in humans [114].

Oxidative signaling and oxidative stress are effectors of the immune response in many central nervous system diseases [115], and it is likely that the balance of oxidative stress and antioxidants influences response to and recovery from SAH. Haptoglobin is a serum protein composed of tetramer of two $\alpha$ and two $\beta$ chains. Its main action is to bind free hemoglobin and facilitate its uptake and clearance. This has a net effect of reducing oxidative stress caused by free hemoglobin $[116,117]$. Three phenotypes of haptoglobin (Hp) have been identified in humans: Hp 1-1, Hp 2-1, and Hp 2-2 [118]. In humans, the haptoglobin proteins with $\alpha-2$ subunits have been associated with higher rates of vasospasm compared to haptoglobin $\alpha 1-\alpha 1$ [119]. Similarly, genetically modified Hp 2-2 mice experience increased macrophage infiltration in the subarachnoid space, more severe vasospasm, and worse functional outcome after SAH [120]. Recently, Hp 2-2 phenotype was associated with neurological deterioration but not cerebral infarction or unfavorable outcome in one clinical SAH study [121]; however, another recent study did find worse clinical outcomes in patients with the 2-2 phenotype [122]. Ongoing work in this area will further clarify the role of haptoglobin phenotype in SAH.

Endothelium-derived relaxing factor or nitric oxide (NO) is synthesized enzymatically by three main nitric oxide synthase (NOS) isoforms, endothelial (eNOS), neuronal (nNOS), and macrophage inducible NOS (iNOS) [123]. Under physiologic conditions, NO affects signaling pathways for vasodilation and cytoprotection among many others [123, 124]. The function of eNOS can be altered in many disease states such as atherosclerosis, hypertension, and diabetes mellitus, in which case eNOS starts to produce superoxide anion $\left(\mathrm{O}_{2}{ }^{-}\right)$instead of $\mathrm{NO}$, an alteration defined as "eNOS uncoupling" [125]. Increased eNOS and iNOS expression were detected in mice after $\mathrm{SAH}$, and this physiological response to $\mathrm{SAH}$ is decreased in proinflammatory $\mathrm{Hp} 2$ 2 transgenic mice compared with $\mathrm{Hp}$ 1-1 mice [126, 127]. In an animal model of $\mathrm{SAH}$, simvastatin was shown to recouple eNOS and improve outcome after SAH [128]. On the other hand, genetic elimination of eNOS in knockout mice reduces the incidence of vasospasm and reduces oxidative stress as measured by superoxide production but has no effect on iNOS [129]. eNOS knockout mice also exhibit reduced
$\mathrm{Zn}^{2+}$ release after $\mathrm{SAH}$, which was associated with reduced microthrombi formation and neuronal degeneration in the same experiment.

Endothelins, which are potent vasoconstrictors and proinflammatory mediators expressed by vascular endothelial cells and vascular smooth muscle cells [130], are thought to contribute to tissue inflammation and cerebral edema. Several studies have documented increased ET-1 levels in SAH patients with symptomatic vasospasm and that the amount of blood within the cisterns correlated with the level of ET-1 in CSF [73, 76, 131]. However, other studies have failed to find significant elevation of ET-1 after SAH or a correlation between ET-1 levels and vasospasm [16, 73]. Inhibition of ET-1 by administration of anti-ET-1 monoclonal antibodies [132], anti-ET receptor antibodies [74, 133], ET activation enzyme inhibitors [134], and levosimendan (which antagonizes the ET receptor) [135] was effective in decreasing vasospasm in some $[74,133]$ but not all studies $[135,136]$. Transgenic mice overexpressing ET-1 experienced more pronounced vasospasm and cerebral edema and an ETA receptor antagonist decreased vasospasm and edema in the same study [137].

4.3. Trials of Anti-Inflammatory Agents for Treatment of Vasospasm. As subarachnoid blood is thought to generate much of the acute inflammation in SAH, faster clearance of subarachnoid clot could potentially improve outcomes after SAH. This theory has been tested, and intrathecal administration of thrombolytic agents has decreased vasospasm and improved outcomes in primates [138] and humans [139143] after SAH. A meta-analysis showed a beneficial effect of thrombolytic treatment, with absolute risk reductions of $14.4 \%$; however, the results of the analysis were limited due to predominance of nonrandomized studies [144]. In a recent clinical study by Yamamoto et al., cisternal irrigation therapy using tissue plasminogen activator in patients who underwent surgical clipping of ruptured intracranial aneurysms decreased serum inflammatory markers, reduced the incidence of ischemic lesions, and was associated with better neurological outcome [145]. Kim and colleagues recently demonstrated that cisternal irrigation with papaverine, a phosphodiesterase inhibitor and potent vasodilator, was similar in effectiveness compared to the thrombolytic urokinase, both of which decreased incidence of vasospasm [146].

Corticosteroids are potent anti-inflammatories and have been used in several human SAH trials. Experimental administration of high-dose methylprednisolone has been shown to reduce angiographic vasospasm and ameliorate arterial wall abnormalities in dog models [147-149]. Human clinical studies by Chyatte and colleagues [150] showed that highdose methylprednisolone treatment improved neurological outcomes, reduced mortality, and delayed cerebral ischemia. A multicenter study of intravenous hydrocortisone administration after SAH showed improved mental status, speech, and motor function at 1 month after treatment [151]. However, another randomized controlled trial of hydrocortisone did not show any effect on neurological outcome after $\mathrm{SAH}$ [152]. On the other hand, hydrocortisone has been shown to support hypervolemic therapy by attenuating natriuresis 
[153], inducing hypervolemia, and improving the efficiency of hypervolemic therapy [154]. However, a large double blind randomized control trial demonstrated a beneficial effect of methylprednisolone in functional outcome one year after SAH but no effect on vasospasm [155]. These studies underscore the fact that outcomes in SAH are not solely dependent upon the development of vasospasm.

Nonsteroidal anti-inflammatory drugs (NSAIDs) also have potent anti-inflammatory properties, mediated in part by inhibition of cyclooxygenase expression, which reduces prostaglandin synthesis [156]. NSAID administration significantly reduced the severity of vasospasm in an animal model of SAH; however, the mode of NSAID treatment in this model, 30 minutes before and 3 hours after SAH, is not applicable to human trials [157]. Ibuprofen inhibits femoral artery vasospasm and decreases periadventitial monocytes and macrophages after, in a rodent model of $\mathrm{SAH}$, and can increase cerebrovascular diameter in monkeys and rabbits [158-160]. Chyatte and colleagues also demonstrated that ibuprofen prevented ultrastructural changes in the cerebral vessel walls of dogs after blood injection [149]. The nonsteroidal anti-inflammatory drugs parecoxib and celecoxib have also shown promise as treatment options for vasospasm [161-163]. As these drugs are relatively safe and well studied in humans, they hold promise for clinically applicable treatment options for vasospasm.

Immunosuppressants such as cyclosporine cause T-cell dysfunction by inhibiting interleukin-2 (IL-2) transcription [164] and have been tested in experimental SAH with varied success $[165,166]$. Clinical studies with cyclosporine are also varied, showing no beneficial effect of cyclosporine in the outcome patients with severe SAH [167], but showing improved outcome in patients who underwent early clipping after SAH when combined with nimodipine [168-170]. Tacrolimus (FK-506), a newer immunosuppressant, did not prevent vasoconstriction and lymphocytic infiltrations in experimental SAH models [171-173].

Statins are 3-hydroxy-3-methylglutaryl coenzyme A reductase inhibitors clinically used as cholesterol-reducing agents. Their ability to reduce the expression of proinflammatory cytokines and inhibit leukocyte integrins confers their potent anti-inflammatory activity $[174,175]$. Preconditioning of rats with atorvastatin has been shown to reduce the level of ET-1 while attenuating vasospasm, which could be a mechanism of antivasospastic effects of statins after SAH [176]. Simvastatin treatment before or after SAH was also shown to attenuate cerebral vasospasm and neurological deficits, possibly via endothelial nitric oxide upregulation [177], and decrease perivascular granulocyte migration [40]. Several clinical studies have shown that statins decrease serum ICAM-1 levels in hypercholesterolemic patients [174, $175,178-180]$, which could explain the experimental findings associated with decreased leukocyte migration. However, clinical studies with statins have yielded mixed results. While one study showed improved 14-day functional outcomes and cerebral vasospasm in patients receiving statins prior to their SAH [181], more recent studies [182, 183] did not find significant differences in the severity of angiographic or clinical vasospasm or neurologic outcomes of patients receiving statins after SAH. Another case-control study showed that oral atorvastatin treatment decreased vasospasm and cerebral ischemia but did not lead to significant functional improvement 1 year after SAH [184]. In a phase-II randomized controlled trial enrolling 80 patients with SAH, patients treated with oral pravastatin 72 hours after SAH had a $32 \%$ reduction in vasospasm incidence, and vasospasmrelated neurologic deficits and mortality were decreased by $83 \%$ and $75 \%$, respectively [185]. Subsequently, pravastatin was also effective at sustaining the improved neurological outcome at 6 months after the treatment [186]. A Cochrane review of clinical trials on statins after SAH concluded that, in the only clinical trial that met criteria, although simvastatin improved vasospasm, mortality, and functional outcome, these benefits were not statistically significant [187]. Currently, clinical trials including simvastatin in aneurysmal subarachnoid hemorrhage (STASH) trial are ongoing (http://clinicaltrials.gov/show/NCT00731627).

Nitric oxide (NO) depletion contributes to the pathogenesis of cerebral vasospasm after SAH $[188,189]$. Therefore, several NO donors have been investigated for treatment of vasospasm. Intrathecal NO supplementation via controlledreleased polymers was shown to prevent vasospasm in rat and rabbit models of SAH $[190,191]$ and delayed polymer implantation 24 or 48 hours after SAH has been shown to be still effective at ameliorating vasospasm [191]. Several other studies have also shown that selective intracerebral NO injection, [192] intraventricular NO injection [193], and systemic nitrite infusions can improve the severity or decrease the incidence of vasospasm in experimental and clinical studies [189]. Intravenous sodium nitrate $\left(\mathrm{NaNO}_{2}\right)$ was also shown to reduce the degree of vasospasm and nitrite, nitrate, and S-nitrosothiols concentrations in CSF were found to be increased compared to controls in primate model of SAH [194]. L-citrulline is an amino acid that when converted to L-arginine increases nitric oxide (NO) production by NO synthase (NOS), leading to vasodilation [195]. L-citrulline administration has been shown to prevent posthemorrhagic cerebral vasospasm in the transgenic Hp 2-2 model of SAH, improve neurological function as determined by PGA (posture, grooming, and ambulation) scores, and reverse the decrease in upregulation of iNOS and eNOS expression in Hp 2-2 animals compared with baseline levels in mice [126]. Besides vasodilation, NO supplementation can have anti-inflammatory effects through modulating leukocyte-endothelial cell interactions in the acute inflammatory response. Inhibitors of NO production increase leukocyte adherence [196], and NO modulates oxidative stress [197] and microvascular permeability $[198,199]$. The antiinflammatory effects of NO through prevention of leukocyte adhesion have been linked with its ability to inactivate the superoxide anion [200]. Besides ameliorating vasospasm, whether NO donors including citrulline can help recoupling of eNOS, decrease the inflammatory infiltration, and decrease neuronal apoptosis requires further investigation. Other NO donors such as sodium nitroprusside and nitroglycerin are not considered as potential candidates due to their side effects such as dose-limiting hypotension, cyanide toxicity, and tolerance development [201]. 
Clazosentan, a synthetic endothelin receptor antagonist (ETRA), has been investigated as a potential treatment for vasospasm after subarachnoid hemorrhage [202]. In the CONSCIOUS-1 trial, an intravenous infusion of clazosentan $5 \mathrm{mg} / \mathrm{h}$ decreased vasospasm but the study was not powered to detect changes in morbidity and mortality [203]. In CONSCIOUS-2, a phase-III randomized controlled trial, including 1,157 patients, clazosentan infusion up to 14 days after hemorrhage did not reduce vasospasm-related morbidity and mortality or improve functional outcome [75]. A meta-analysis of randomized controlled trials for ETRAs for the treatment of vasospasm, including 5 trials with 2601 patients, showed that ETRAs decreased incidence of angiographic vasospasm; however, they did not improve functional outcome, vasospasm-related cerebral infarction, or mortality [204]. As a result, the use of ETRAs in patients with SAH was not proven to be beneficial [204]. These studies reinforce that vasospasm alone cannot be accounted for the neurological deficits and functional outcome after SAH and treatment strategies that only target improving or preventing vasospasm are not likely to succeed.

Cilostazol is a selective phosphodiesterase III inhibitor that is used to treat ischemic peripheral vascular disease and exhibits anti-inflammatory properties including inhibiting microglial activation [205, 206]. Oral cilostazol administration prevented vasospasm in a rat model of SAH [207] and reduced endothelial damage in a canine model of SAH [208]. Clinical studies have demonstrated effectiveness of cilostazol in decreasing incidence and severity of vasospasm [209, 210]. A multicenter randomized clinical trial of cilostazol has shown a decrease in angiographic vasospasm but no improvement in outcomes 6 months after SAH [211].

\section{The Role of Inflammation in Early Brain Injury and Delayed Neurological Deterioration after SAH}

While there is no doubt that inflammation occurs after $\mathrm{SAH}$, a link must be made between inflammation and poor outcomes after SAH for it to be considered an important therapeutic target. As demonstrated by several of the trials discussed above, vasospasm is not the only determinant of outcome after SAH. It is likely that inflammation plays multiple roles after $\mathrm{SAH}$, mediating vasospasm as tissue damage as well as leading to regeneration or recovery as has been shown in other neurological conditions [212]. Alternately, the inflammatory cytokines detected in the CSF and blood after SAH could be results, rather than causative factors, of brain injury after SAH. There is a vast literature in ischemic stroke that ties the inflammatory response to deleterious effects such as edema and neuronal loss. Many experimental studies in stroke have shown blood brain barrier breakdown to be mediated by inflammatory cytokines [213] and that inhibiting inflammation reduces cerebral edema and neurological injury $[214,215]$. Proinflammatory cytokines such as TNF $\alpha$, IL-1, IL-6, and leukocyte adhesion molecules have been associated with worse outcomes in ischemic stroke [216]. However, despite the vast literature on inflammation in ischemic stroke, there have been no successful clinical trials using anti-inflammatory agents.

Recently, the term "early brain injury" has been used to describe the mechanisms of acute neurologic deterioration after SAH [217]. Early brain injury includes cell death, cerebral edema, and neuronal dysfunction that occur after SAH. Although vasospasm is a major cause of clinical deterioration after SAH, recent thinking has focused on the fact that vasospasm is not the only phenomenon contributing to poor patient outcomes after SAH [218, 219]. A key example of this is that nimodipine, the only pharmaceutical treatment shown to improve outcomes in SAH, appears to manifest its effects without affecting the rate of vasospasm [220, 221]. Many patients also undergo neurological deterioration in a delayed fashion after SAH. This can be due to cerebral vasospasm, which typically peaks 7 to 14 days after SAH, but also occurs in the absence of vasospasm. This subacute neurological decline is referred to as "delayed neurological deterioration" and can be mediated by several events including delayed ischemia (with or without vasospasm), seizures, and fevers [222]. The terms "delayed neurological deterioration (DND)" and "delayed cerebral ischemia (DCI)" are often used interchangeably, but it should be noted that DCI is just one of the causes of DND [223]. Additionally, it is likely that the events of early brain injury occur along a continuum with DND and are likely mediated by many of the same factors.

As in ischemic stroke, there is no accepted use of antiinflammatory treatments for improving outcome after SAH. As discussed earlier, corticosteroids have been used to block inflammation after SAH, but there is no clear therapeutic benefit of this strategy [224]. However, there is experimental evidence from animal studies showing that blocking inflammatory pathways can improve both blood brain barrier breakdown and neuronal survival after SAH [219, 225]. In one study utilizing a rat model of $\mathrm{SAH}$, there was a reduction in $\mathrm{TNF} \alpha$ production, cerebral edema, and apoptosis in response to a blockade of a sulfonylurea receptor that is upregulated after SAH [45].

Clinically, the presence of cell death, cerebral edema, and vasospasm all contribute to poor outcomes after SAH. Though it is difficult to measure cell loss in humans, there is evidence for hippocampal neuronal loss after SAH based on MRI imaging, and elevated neurofilament levels in CSF correlate with functional outcome after SAH, indicating a link between axonal breakdown and clinical outcome [226, 227]. As in ischemic stroke, proinflammatory cytokines have gained attention as biomarkers for outcome in $\mathrm{SAH}$, and the recent literature is well reviewed by Lad and colleagues [228]. Genetic differences in inflammatory cytokine expression and haptoglobin phenotype (discussed previously) have also been used to prognosticate outcome in patients with $\mathrm{SAH}$, without definitive results [69]. Human genetic studies have also shown a benefit of lower TNF $\alpha$ levels for recovery after SAH [229]. This points to a possible dual role for inflammation in both acute injury and recovery, as has been proposed in other neurological diseases [230]. There is already experimental support for this dual role of inflammation in $\mathrm{SAH}$, as the cytokine MCP-1 that has been associated with poor outcomes 
TABLE 1: Key inflammatory molecules implicated in the pathology of SAH.

\begin{tabular}{|c|c|c|c|c|}
\hline Molecule & Function & Roles in animal studies & Roles in human studies & Comments \\
\hline Selectins & Leukocyte adhesion & $\begin{array}{l}\text { Inhibition of selectins } \\
\text { decreases vasospasm } \\
{[62,63]}\end{array}$ & $\begin{array}{l}\text { Higher levels in CSF correlate } \\
\text { to vasospasm in some studies } \\
\text { [3], found in walls of ruptured } \\
\text { aneurysms [36] }\end{array}$ & $\begin{array}{l}\text { Variable expression in patients with } \\
\text { SAH }[3,8,9] \text {, used to prognosticate } \\
\text { outcome in critically ill patients } \\
\text { without SAH [28] }\end{array}$ \\
\hline Integrins & Leukocyte adhesion & $\begin{array}{l}\text { Blocking reduces } \\
\text { vasospasm [64-66] }\end{array}$ & $\begin{array}{l}\text { Higher levels seen in patients } \\
\text { with vasospasm [3] }\end{array}$ & \\
\hline $\mathrm{TNF} \alpha$ & $\begin{array}{l}\text { Proinflammatory } \\
\text { cytokine produced by } \\
\text { leukocytes }\end{array}$ & $\begin{array}{l}\text { Induces neuronal apoptosis } \\
\text { after SAH [52]; blockade } \\
\text { reduces vasospasm [67] }\end{array}$ & $\begin{array}{l}\text { Found in CSF in patients after } \\
\text { SAH and correlates with } \\
\text { vasospasm after SAH [68] }\end{array}$ & $\begin{array}{l}\text { Variable expression in patients with } \\
\text { SAH }[2,10-12]\end{array}$ \\
\hline MCP-1 & $\begin{array}{l}\text { Macrophage } \\
\text { chemoattractant }\end{array}$ & $\begin{array}{l}\text { Promotes repair of } \\
\text { aneurysms [69] }\end{array}$ & $\begin{array}{l}\text { Found in CSF after SAH and } \\
\text { associated with poor outcomes } \\
\text { but not vasospasm }[9,21]\end{array}$ & $\begin{array}{l}\text { Also associated with vascular injury } \\
\text { [31] }\end{array}$ \\
\hline ICAM-1 & Leukocyte adhesion & $\begin{array}{l}\text { Increased in animal SAH } \\
\text { studies }[47,70] \text {; blockade } \\
\text { reduces vasospasm [71] }\end{array}$ & $\begin{array}{l}\text { Increased in patients with } \\
\mathrm{SAH}[3]\end{array}$ & $\begin{array}{l}\text { Used to prognosticate outcome in } \\
\text { critically ill patients without SAH } \\
{[28]}\end{array}$ \\
\hline Interleukins & $\begin{array}{l}\text { Mediate leukocyte } \\
\text { interactions }\end{array}$ & $\begin{array}{l}\text { Blockade reduces } \\
\text { vasospasm [72] }\end{array}$ & Peak early in SAH $[9,11]$ & $\begin{array}{l}\text { Peak at variable times in human } \\
\text { studies }[29,30]\end{array}$ \\
\hline Endothelin-1 & $\begin{array}{l}\text { Potent } \\
\text { vasoconstrictor }\end{array}$ & $\begin{array}{l}\text { Inhibition reduces } \\
\text { vasospasm }[73,74]\end{array}$ & $\begin{array}{l}\text { Produced by monocytes from } \\
\text { SAH patients }[13,14] \text {, with no } \\
\text { proved benefit in clinical trials } \\
{[75]}\end{array}$ & $\begin{array}{l}\text { Highly variable expression after } \\
\text { SAH and may not correlate with } \\
\text { vasospasm }[13,16,76]\end{array}$ \\
\hline
\end{tabular}

and vasospasm after SAH has recently been used to promote repair of experimental aneurysms [21, 231].

\section{Discussion}

Evidence from both clinical and animal studies indicates that inflammation contributes to aneurysm formation, brain injury, and vasospasm after SAH and that many of the same molecules contribute to vasospasm and brain injury after SAH (Figure 1, Table 1). Much of the data from human studies linking inflammation to worse outcomes after SAH is correlative and studies examining different inflammatory molecules at different time points after SAH make it difficult to make direct comparisons (Table 1). However, taken together, human and animal studies suggest that a higher "inflammatory burden" contributes to the pathophysiology of SAH. This would suggest anti-inflammatory treatment to be a robust treatment strategy for $\mathrm{SAH}$, as in other diseases. For example, the possibility that aspirin could reduce chronic inflammation within the walls of aneurysms and decrease the risk of rupture $[34,35]$ is akin to the paradigm of human cardiovascular disease in which the anti-inflammatory actions of aspirin and statins may protect against cardiovascular disease $[122,232,233]$. Unfortunately, this strategy has not borne out reliably in clinical trials. One potential reason for this is that animal studies of homogenous populations may not be an accurate model of SAH in humans where individual responses to a given insult could be quite variable.

Clinicians who care for patients with SAH understand that there is a wide range of physiologic responses to $\mathrm{SAH}$, even in patients who present with the same initial grade of hemorrhage. While this is doubtlessly influenced by many factors (such as SAH blood volume), the intensity of an

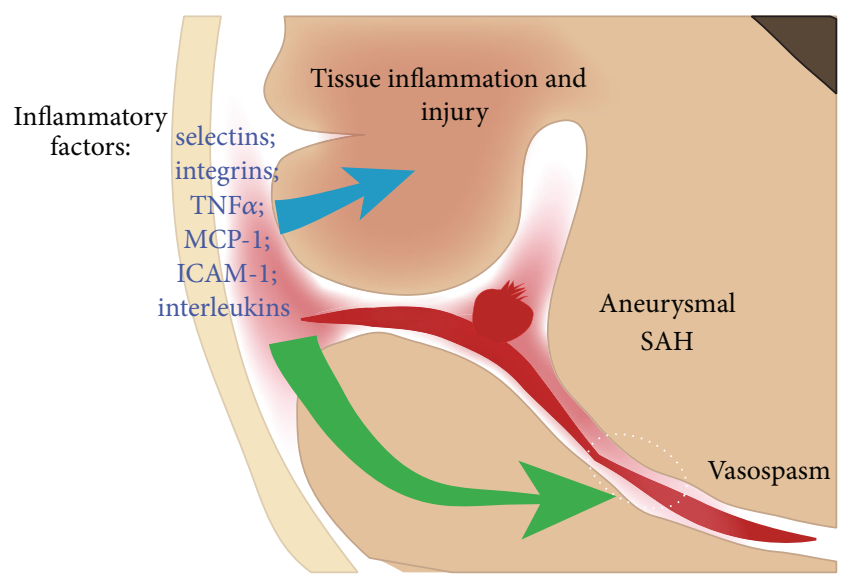

FIgURE 1: Schematic of a coronal projection of a ruptured cerebral aneurysm and contributing factors that result in cerebral vasospasm after SAH and delayed ischemic injury. Many inflammatory factors are hypothesized to contribute to brain injury and vasospasm after $\mathrm{SAH}$. The interface between subarachnoid blood, brain parenchyma, and the cerebral vasculature is the likely location for induction of inflammatory cascades that lead to brain injury and vasospasm after SAH.

individual's inflammatory response to SAH may also determine if a patient develops delayed clinical deterioration or vasospasm. While this could be influenced by factors such as haptoglobin genotype [122], there are probably other genetic and environmental factors that influence patients' production of, and tolerance to, a post-SAH inflammatory response. Evidence from animal studies has shown that inflammatory stimuli can both exacerbate and reduce vasospasm, depending on the intensity of the stimulus [234]. A recent 
clinical study implied that preexisting atherosclerotic disease could have a protective effect on patients who suffer SAH, possibly by modifying neuroinflammation [233, 235, 236]. In the future, treatment for $\mathrm{SAH}$ may involve tailoring therapy to match the timing and intensity of an individual patient's inflammatory response. In order for this approach to be implemented, successful validation of inflammatory biomarkers and outcome measures for SAH would need to be developed.

\section{Conclusion}

The immune response within (and possibly outside of) the CNS is clearly a driving force behind many of the pathological events of SAH, including both vasospasm and early brain injury. Though much experimental and clinical work has linked increased inflammation to poor outcome after SAH, there is still no proven anti-inflammatory treatment that can be offered to patients who have suffered SAH. The volume of research on inflammation and SAH is rapidly expanding and will likely lead to new clinical trials, development of biomarkers, and hopefully anti-inflammatory treatments for SAH. Though anti-inflammatory treatments will likely improve the lives of patients with SAH, it must be remembered that neuroinflammation has beneficial effects as well and could also play a role in recovery after SAH.

\section{Conflict of Interests}

The authors declare that there is no conflict of interests regarding the publication of this paper.

\section{Acknowledgments}

Brandon A. Miller received NIH R25 Fellowship Award and AANS/CNS Robert J. Dempsey Cerebrovascular Section Award.

\section{References}

[1] M. Y. Kaynar, T. Tanriverdi, A. M. Kafadar et al., "Detection of soluble intercellular adhesion molecule-1 and vascular cell adhesion molecule-1 in both cerebrospinal fluid and serum of patients after aneurysmal subarachnoid hemorrhage," Journal of Neurosurgery, vol. 101, no. 6, pp. 1030-1036, 2004.

[2] T. Kikuchi, Y. Okuda, N. Kaito, and T. Abe, "Cytokine production in cerebrospinal fluid after subarachnoid haemorrhage," Neurological Research, vol. 17, no. 2, pp. 106-108, 1995.

[3] R. S. Polin, M. Bavbek, M. E. Shaffrey et al., "Detection of soluble E-selectin, ICAM-1, VCAM-1, and L-selectin in the cerebrospinal fluid of patients after subarachnoid hemorrhage," Journal of Neurosurgery, vol. 89, no. 4, pp. 559-567, 1998.

[4] G. H. Danton and W. D. Dietrich, "Inflammatory mechanisms after ischemia and stroke," Journal of Neuropathology and Experimental Neurology, vol. 62, no. 2, pp. 127-136, 2003.

[5] R. L. Zhang, Z. G. Zhang, M. Chopp, and J. A. Zivin, "Thrombolysis with tissue plasminogen activator alters adhesion molecule expression in the ischemic rat brain," Stroke, vol. 30, no. 3, pp. 624-629, 1999.
[6] C. J. M. Frijns and L. J. Kappell, "Inflammatory cell adhesion molecules in ischemic cerebrovascular disease," Stroke, vol. 33, no. 8, pp. 2115-2122, 2002.

[7] U. C. Schneider, J. Schiffler, N. Hakiy, P. Horn, and P. Vajkoczy, "Functional analysis of Pro-inflammatory properties within the cerebrospinal fluid after subarachnoid hemorrhage in vivo and in vitro," Journal of Neuroinflammation, vol. 9, article 28, 2012.

[8] T. Tanriverdi, G. Z. Sanus, M. O. Ulu et al., "Serum and cerebrospinal fluid concentrations of E-selectin in patients with aneurysmal subarachnoid hemorrhage," Brazilian Journal of Medical and Biological Research, vol. 38, no. 11, pp. 1703-1710, 2005.

[9] P. Gaetani, F. Tartara, P. Pignatti, F. Tancioni, R. Rodriguez Y Baena, and F. de Benedetti, "Cisternal CSF levels of cytokines after subarachnoid hemorrhage," Neurological Research, vol. 20, no. 4, pp. 337-342, 1998.

[10] X. Xie, X. Wu, J. Cui, H. Li, and X. Yan, "Increase ICAM-1 and LFA-1 expression by cerebrospinal fluid of subarachnoid hemorrhage patients: involvement of TNF- $\alpha$," Brain Research, vol. 1512, pp. 89-96, 2013.

[11] K. Fassbender, B. Hodapp, S. Rossol et al., "Inflammatory cytokines in subarachnoid haemorrhage: association with abnormal blood flow velocities in basal cerebral arteries," Journal of Neurology Neurosurgery and Psychiatry, vol. 70, no. 4, pp. 534-537, 2001.

[12] S. J. Hopkins, C. J. McMahon, N. Singh et al., "Cerebrospinal fluid and plasma cytokines after subarachnoid haemorrhage: CSF interleukin- 6 may be an early marker of infection," Journal of Neuroinflammation, vol. 9, article 255, 2012.

[13] K. Fabender, B. Hodapp, S. Rossol et al., "Endothelin-1 in subarachnoid hemorrhage: an acute-phase reactant produced by cerebrospinal fluid leukocytes," Stroke, vol. 31, no. 12, pp. 2971-2975, 2000.

[14] H. Masaoka, R. Suzuki, Y. Hirata, T. Emori, F. Marumo, and K. Hirakawa, "Raised plasma endothelin in aneurysmal subarachnoid haemorrhage," The Lancet, vol. 2, no. 8676, p. $1402,1989$.

[15] H. Ehrenreich, M. Lange, K. A. Near et al., "Long term monitoring of immunoreactive endothelin-1 and endothelin3 in ventricular cerebrospinal fluid, plasma, and 24-h urine of patients with subarachnoid hemorrhage," Research in Experimental Medicine, vol. 192, no. 1, pp. 257-268, 1992.

[16] G. Hamann, E. Isenberg, M. Strittmatter, and K. Schimrigk, "Absence of elevation of big endothelin in subarachnoid hemorrhage," Stroke, vol. 24, no. 3, pp. 383-386, 1993.

[17] T. Sozen, R. Tsuchiyama, Y. Hasegawa et al., "Immunological response in early brain injury after SAH," Acta Neurochirurgica, Supplementum, no. 110, part 1, pp. 57-61, 2011.

[18] J. Claassen, J. R. Carhuapoma, K. T. Kreiter, E. Y. Du, E. S. Connolly, and S. A. Mayer, "Global cerebral edema after subarachnoid hemorrhage: frequency, predictors, and impact on outcome," Stroke, vol. 33, no. 5, pp. 1225-1232, 2002.

[19] S. Horstmann, Y. Su, J. Koziol, U. Meyding-Lamadé, S. Nagel, and S. Wagner, "MMP-2 and MMP-9 levels in peripheral blood after subarachnoid hemorrhage," Journal of the Neurological Sciences, vol. 251, no. 1-2, pp. 82-86, 2006.

[20] J. Mocco, W. J. Mack, G. H. Kim et al., "Rise in serum soluble intercellular adhesion molecule-1 levels with vasospasm following aneurysmal subarachnoid hemorrhage," Journal of Neurosurgery, vol. 97, no. 3, pp. 537-541, 2002.

[21] G. H. Kim, C. P. Kellner, D. K. Hahn et al., "Monocyte chemoattractant protein-1 predicts outcome and vasospasm 
following aneurysmal subarachnoid hemorrhage," Journal of Neurosurgery, vol. 109, no. 1, pp. 38-43, 2008.

[22] W. J. Mack, J. Mocco, D. J. Hoh et al., "Outcome prediction with serum intercellular adhesion molecule-1 levels after aneurysmal subarachnoid hemorrhage," Journal of Neurosurgery, vol. 96, no. 1, pp. 71-75, 2002.

[23] J. J. Nissen, D. Mantle, A. Blackburn et al., "The selectin superfamily: the role of selectin adhesion molecules in delayed cerebral ischaemia after aneurysmal subarachnoid haemorrhage," Acta Neurochirurgica, Supplement, vol. 76, pp. 55-60, 2000 .

[24] Y. Kubo, K. Ogasawara, S. Kakino et al., "Serum inflammatory adhesion molecules and high-sensitivity C-reactive protein correlates with delayed ischemic neurologic deficits after subarachnoid hemorrhage," Surgical Neurology, vol. 69, no. 6, pp. 592-596, 2008.

[25] R. Dhar and M. N. Diringer, "The burden of the systemic inflammatory response predicts vasospasm and outcome after subarachnoid hemorrhage," Neurocritical Care, vol. 8, no. 3, pp. 404-412, 2008.

[26] A. K. H. Tam, D. Ilodigwe, J. Mocco et al., "Impact of systemic inflammatory response syndrome on vasospasm, cerebral infarction, and outcome after subarachnoid hemorrhage: exploratory analysis of CONSCIOUS-1 database," Neurocritical Care, vol. 13, no. 2, pp. 182-189, 2010.

[27] C. Muroi, M. Hugelshofer, M. Seule et al., "Correlation among systemic inflammatory parameter, occurrence of delayed neurological deficits, and outcome after aneurysmal subarachnoid hemorrhage," Neurosurgery, vol. 72, no. 3, pp. 367-375, 2013.

[28] R. de Pablo, J. Monserrat, E. Reyes et al., "Circulating sICAM1 and sE-Selectin as biomarker of infection and prognosis in patients with systemic inflammatory response syndrome," European Journal of Internal Medicine, vol. 24, no. 2, pp. 132$138,2013$.

[29] T. Takizawa, T. Tada, K. Kitazawa et al., "Inflammatory cytokine cascade released by leukocytes in cerebrospinal fluid after subarachnoid hemorrhage," Neurological Research, vol. 23, no. 7, pp. 724-730, 2001.

[30] T. Mathiesen, B. Andersson, A. Loftenius, and H. von Holst, "Increased interleukin-6 levels in cerebrospinal fluid following subarachnoid hemorrhage," Journal of Neurosurgery, vol. 78, no. 4, pp. 562-567, 1993.

[31] T. Aoki and M. Nishimura, "Targeting chronic inflammation in cerebral aneurysms: focusing on NF- $\kappa \mathrm{B}$ as a putative target of medical therapy," Expert Opinion on Therapeutic Targets, vol. 14, no. 3, pp. 265-273, 2010.

[32] T. Aoki, H. Kataoka, R. Ishibashi, K. Nozaki, K. Egashira, and N. Hashimoto, "Impact of monocyte chemoattractant protein-1 deficiency on cerebral aneurysm formation," Stroke, vol. 40, no. 3, pp. 942-951, 2009.

[33] D. Hasan, T. Hashimoto, D. Kung, R. Loch MacDonald, H. Richard Winn, and D. Heistad, "Upregulation of cyclooxygenase-2 (COX-2) and microsomal prostaglandin E2 synthase1 (mPGES-1) in wall of ruptured human cerebral aneurysms: preliminary results," Stroke, vol. 43, no. 7, pp. 1964-1967, 2012.

[34] D. M. Hasan, N. Chalouhi, P. Jabbour, V. A. Magnotta, D. K. Kung, and W. L. Young, "Imaging aspirin effect on macrophages in the wall of human cerebral aneurysms using ferumoxytolenhanced MRI: preliminary results," Journal of Neuroradiology, vol. 40, no. 3, pp. 187-191, 2013.
[35] D. M. Hasan, K. B. Mahaney, R. D. Brown et al., "Aspirin as a promising agent for decreasing incidence of cerebral aneurysm rupture," Stroke, vol. 42, no. 11, pp. 3156-3162, 2011.

[36] W. Jia, R. Wang, J. Zhao et al., "E-selectin expression increased in human ruptured cerebral aneurysm tissues," Canadian Journal of Neurological Sciences, vol. 38, no. 6, pp. 858-862, 2011.

[37] N. Chalouhi, M. S. Ali, R. M. Starke et al., "Cigarette smoke and inflammation: role in cerebral aneurysm formation and rupture," Mediators of Inflammation, vol. 2012, Article ID 271582, 12 pages, 2012.

[38] N. Chalouhi, B. L. Hoh, and D. Hasan, "Review of cerebral aneurysm formation, growth, and rupture," Stroke, vol. 44, no. 12, pp. 3613-3622, 2013.

[39] S. Marbacher, J. Fandino, and N. D. Kitchen, "Standard intracranial in vivo animal models of delayed cerebral vasospasm," British Journal of Neurosurgery, vol. 24, no. 4, pp. 415-434, 2010.

[40] M. J. McGirt, G. Pradilla, F. G. Legnani et al., "Systemic administration of simvastatin after the onset of experimental subarachnoid hemorrhage attenuates cerebral vasospasm," Neurosurgery, vol. 58, no. 5, pp. 945-951, 2006.

[41] B. H. Han, A. K. Vellimana, M.-L. Zhou, E. Milner, and G. J. Zipfel, "Phosphodiesterase 5 inhibition attenuates cerebral vasospasm and improves functional recovery after experimental subarachnoid hemorrhage," Neurosurgery, vol. 70, no. 1, pp. 178-187, 2012.

[42] O. Altay, Y. Hasegawa, P. Sherchan et al., "Isoflurane delays the development of early brain injury after subarachnoid hemorrhage through sphingosine-related pathway activation in mice," Critical Care Medicine, vol. 40, no. 6, pp. 1908-1913, 2012.

[43] G. F. Prunell, N.-A. Svendgaard, K. Alkass, and T. Mathiesen, "Inflammation in the brain after experimental subarachnoid hemorrhage," Neurosurgery, vol. 56, no. 5, pp. 1082-1091, 2005.

[44] E. Kooijman, C. H. Nijboer, C. T. van Velthoven, A. Kavelaars, J. Kesecioglu, and C. J. Heijnen, "The rodent endovascular puncture model of subarachnoid hemorrhage: mechanisms of brain damage and therapeutic strategies," Journal of Neuroinflammation, vol. 11, no. 1, p. 2, 2014.

[45] J. Marc Simard, Z. Geng, S. Kyoon Woo et al., "Glibenclamide reduces inflammation, vasogenic edema, and caspase-3 activation after subarachnoid hemorrhage," Journal of Cerebral Blood Flow and Metabolism, vol. 29, no. 2, pp. 317-330, 2009.

[46] Y. Handa, T. Kubota, M. Kaneko et al., "Expression of intercellular adhesion molecule 1 (ICAM-1) on the cerebral artery following subarachnoid haemorrhage in rats," Acta Neurochirurgica, vol. 132, no. 1-3, pp. 92-97, 1995.

[47] Y. Aihara, H. Kasuya, H. Onda, T. Hori, and J. Takeda, "Quantitative analysis of gene expressions related to inflammation in canine spastic artery after subarachnoid hemorrhage," Stroke, vol. 32, no. 1, pp. 212-217, 2001.

[48] M.-L. Zhou, W. Wu, Y.-S. Ding et al., "Expression of Toll-like receptor 4 in the basilar artery after experimental subarachnoid hemorrhage in rabbits: a preliminary study," Brain Research, vol. 1173, no. 1, pp. 110-116, 2007.

[49] C.-X. Ma, W.-N. Yin, B.-W. Cai et al., "Toll-like receptor 4/nuclear factor-kappa B signaling detected in brain after early subarachnoid hemorrhage," Chinese Medical Journal, vol. 122, no. 13, pp. 1575-1581, 2009.

[50] O. Altay, H. Suzuki, Y. Hasegawa, R. P. Ostrowski, J. Tang, and J. H. Zhang, "Isoflurane on brain inflammation," Neurobiology of Disease, vol. 62, pp. 365-371, 2013. 
[51] O. Altay, H. Suzuki, Y. Hasegawa et al., "Isoflurane attenuates blood-brain barrier disruption in ipsilateral hemisphere after subarachnoid hemorrhage in mice," Stroke, vol. 43, no. 9, pp. 2513-2516, 2012.

[52] Y. Jiang, D.-W. Liu, X.-Y. Han et al., "Neuroprotective effects of anti-tumor necrosis factor-alpha antibody on apoptosis following subarachnoid hemorrhage in a rat model," Journal of Clinical Neuroscience, vol. 19, no. 6, pp. 866-872, 2012.

[53] J. J. O'Connor, “Targeting tumour necrosis factor- $\alpha$ in hypoxia and synaptic signalling," Irish Journal of Medical Science, vol. 182, no. 2, pp. 157-162, 2013.

[54] V. Friedrich, R. Flores, and F. A. Sehba, "Cell death starts early after subarachnoid hemorrhage," Neuroscience Letters, vol. 512, no. 1, pp. 6-11, 2012.

[55] A. Tariq, J. Ai, G. Chen et al., "Loss of long-term potentiation in the hippocampus after experimental subarachnoid hemorrhage in rats," Neuroscience, vol. 165, no. 2, pp. 418-426, 2010.

[56] H. Jeon, J. Ai, M. Sabri, A. Tariq, and R. L. Macdonald, "Learning deficits after experimental subarachnoid hemorrhage in rats," Neuroscience, vol. 169, no. 4, pp. 1805-1814, 2010.

[57] S. M. Han, H. Wan, G. Kudo et al., "Molecular alterations in the hippocampus after experimental subarachnoid hemorrhage," Journal of Cerebral Blood Flow \& Metabolism, vol. 34, no. 1, pp. 108-117, 2013.

[58] L. Tong, G. Aleph Prieto, E. A. Kramár et al., "Brain-derived neurotrophic factor-dependent synaptic plasticity is suppressed by interleukin-1 $\beta$ via p38 mitogen-activated protein kinase," Journal of Neuroscience, vol. 32, no. 49, pp. 17714-17724, 2012.

[59] J. M. Simard, C. Tosun, S. Ivanova et al., "Heparin reduces neuroinflammation and transsynaptic neuronal apoptosis in a model of subarachnoid hemorrhage," Translational Stroke Research, vol. 3, supplement 1, pp. 155-165, 2012.

[60] P. M. Cobelens, I. A. C. W. Tiebosch, R. M. Dijkhuizen et al., "Interferon- $\beta$ attenuates lung inflammation following experimental subarachnoid hemorrhage," Critical Care, vol. 14, no. 4, article R157, 2010.

[61] K. E. Wartenberg and S. A. Mayer, "Medical complications after subarachnoid hemorrhage," Neurosurgery Clinics of North America, vol. 21, no. 2, pp. 325-338, 2010.

[62] C.-L. Lin, A. S. Dumont, T. Calisaneller, A.-L. Kwan, S.L. Hwong, and K. S. Lee, "Monoclonal antibody against E selectin attenuates subarachnoid hemorrhage-induced cerebral vasospasm," Surgical Neurology, vol. 64, no. 3, pp. 201-206, 2005.

[63] T. Nakayama, K. Illoh, C. Ruetzler, S. Auh, L. Sokoloff, and J. Hallenbeck, "Intranasal administration of E-selectin to induce immunological tolerization can suppress subarachnoid hemorrhage-induced vasospasm implicating immune and inflammatory mechanisms in its genesis," Brain Research, vol. 1132, no. 1, pp. 177-184, 2007.

[64] R. E. Clatterbuck, E. M. Oshiro, P. A. Hoffman, G. N. Dietsch, D. M. Pardoll, and R. J. Tamargo, "Inhibition of vasospasm with lymphocyte function-associated antigen-1 monoclonal antibody in a femoral artery model in rats," Journal of Neurosurgery, vol. 97, no. 3, pp. 676-682, 2002.

[65] G. Pradilla, P. P. Wang, F. G. Legnani, L. Ogata, G. N. Dietsch, and R. J. Tamargo, "Prevention of vasospasm by antiCD11/CD18 monoclonal antibody therapy following subarachnoid hemorrhage in rabbits," Journal of Neurosurgery, vol. 101, no. 1, pp. 88-92, 2004.

[66] R. E. Clatterbuck, P. Gailloud, L. Ogata et al., "Prevention of cerebral vasospasm by a humanized anti-CD11/CD18 monoclonal antibody administered after experimental subarachnoid hemorrhage in nonhuman primates," Journal of Neurosurgery, vol. 99, no. 2, pp. 376-382, 2003.

[67] H. Jȩdrzejowska-Szypułka, M. Larysz-Brysz, M. Kukla, M. Śnietura, and J. Lewin-Kowalik, "Neutralization of interleukin$1 \beta$ reduces vasospasm and alters cerebral blood vessel density following experimental subarachnoid hemorrhage in rats," Current Neurovascular Research, vol. 6, no. 2, pp. 95-103, 2009.

[68] K. A. Hanafy, R. M. Stuart, A. G. Khandji et al., "Relationship between brain interstitial fluid tumor necrosis factor- $\alpha$ and cerebral vasospasm after aneurysmal subarachnoid hemorrhage," Journal of Clinical Neuroscience, vol. 17, no. 7, pp. 853856, 2010.

[69] A. F. Ducruet, P. R. Gigante, Z. L. Hickman et al., "Genetic determinants of cerebral vasospasm, delayed cerebral ischemia, and outcome after aneurysmal subarachnoid hemorrhage," Journal of Cerebral Blood Flow and Metabolism, vol. 30, no. 4, pp. 676-688, 2010.

[70] C.-L. Lin, A.-L. Kwan, A. S. Dumont et al., "Attenuation of experimental subarachnoid hemorrhage-induced increases in circulating intercellular adhesion molecule-1 and cerebral vasospasm by the endothelin-converting enzyme inhibitor CGS 26303," Journal of Neurosurgery, vol. 106, no. 3, pp. 442-448, 2007.

[71] M. Bavbek, R. Polin, A.-L. Kwan, A. S. Arthur, N. F. Kassell, and K. S. Lee, "Monoclonal antibodies against ICAM-1 and CD18 attenuate cerebral vasospasm after experimental subarachnoid hemorrhage in rabbits," Stroke, vol. 29, no. 9, pp. 1930-1936, 1998.

[72] G. Bowman, R. H. Bonneau, V. M. Chinchilli, K. J. Tracey, and K. M. Cockroft, "A novel inhibitor of inflammatory cytokine production (CNI-1493) reduces rodent post-hemorrhagic vasospasm," Neurocritical Care, vol. 5, no. 3, pp. 222-229, 2006.

[73] C. S. Jung, B. Lange, M. Zimmermann, and V. Seifert, "The CSF concentration of ADMA, but not of ET-1, is correlated with the occurrence and severity of cerebral vasospasm after subarachnoid hemorrhage," Neuroscience Letters, vol. 524, no. 1, pp. 20-24, 2012.

[74] M. Clozel, V. Breu, K. Burri et al., "Pathophysiological role of endothelin revealed by the first orally active endothelin receptor antagonist," Nature, vol. 365, no. 6448, pp. 759-761, 1993.

[75] R. L. Macdonald, R. T. Higashida, E. Keller et al., "Clazosentan, an endothelin receptor antagonist, in patients with aneurysmal subarachnoid haemorrhage undergoing surgical clipping: a randomised, double-blind, placebo-controlled phase 3 trial (CONSCIOUS-2)," The Lancet Neurology, vol. 10, no. 7, pp. 618$625,2011$.

[76] V. Seifert, B.-M. Loffler, M. Zimmermann, S. Roux, and D. Stolke, "Endothelin concentrations in patients with aneurysmal subarachnoid hemorrhage: correlation with cerebral vasospasm, delayed ischemic neurological deficits, and volume of hematoma," Journal of Neurosurgery, vol. 82, no. 1, pp. 55-62, 1995.

[77] P. Rousseaux, B. Scherpereel, M. H. Bernard, J. P. Graftieaux, and J. F. Guyot, "Fever and cerebral vasospasm in ruptured intracranial aneurysms," Surgical Neurology, vol. 14, no. 6, pp. 459-465, 1980.

[78] B. Weir, L. Disney, M. Grace, and P. Roberts, "Daily trends in white blood cell count and temperature after subarachnoid hemorrhage from aneurysm," Neurosurgery, vol. 25, no. 2, pp. 161-165, 1989. 
[79] J. Oliveira-Filho, M. A. Ezzeddine, A. Z. Segal et al., "Fever in subarachnoid hemorrhage relationship to vasospasm and outcome," Neurology, vol. 56, no. 10, pp. 1299-1304, 2001.

[80] F. Maiuri, B. Gallicchio, P. Donati, and M. Carandente, "The blood leukocyte count and its prognostic significance in subarachnoid hemorrhage," Journal of Neurosurgical Sciences, vol. 31, no. 2, pp. 45-48, 1987.

[81] M. J. McGirt, J. C. Mavropoulos, L. Y. McGirt et al., "Leukocytosis as an independent risk factor for cerebral vasospasm following aneurysmal subarachnoid hemorrhage," Journal of Neurosurgery, vol. 98, no. 6, pp. 1222-1226, 2003.

[82] G. Neil Dwyer and J. Cruickshank, "The blood leucocyte count and its prognostic significance in subarachnoid haemorrhage," Brain, vol. 97, no. 1, pp. 79-86, 1974.

[83] S. Niikawa, S. Hara, N. Ohe, Y. Miwa, and A. Ohkuma, "Correlation between blood parameters and symptomatic vasospasm in subarachnoid hemorrhage patients," Neurologia MedicoChirurgica, vol. 37, no. 12, pp. 881-885, 1997.

[84] A. Spallone, M. Acqui, F. S. Pastore, and B. Guidetti, "Relationship between leukocytosis and ischemic complications following aneurysmal subarachnoid hemorrhage," Surgical Neurology, vol. 27, no. 3, pp. 253-258, 1987.

[85] L. Pellettieri, B. Nilsson, C.-A. Carlsson, and U. Nilsson, "Serum immunocomplexes in patients with subarachnoid hemorrhage," Neurosurgery, vol. 19, no. 5, pp. 767-771, 1986.

[86] J. N. Walton, "The prognosis and management of subarachnoid haemorrhage," Canadian Medical Association Journal, vol. 72, no. 3, pp. 165-175, 1955.

[87] T. Mori, K. Nagata, T. Ishida et al., "Sequential morphological changes of the constrictive basilar artery in a canine model of experimental cerebral vasospasm by talc injection," The Journal of Veterinary Medical Science, vol. 56, no. 3, pp. 535-540, 1994.

[88] K. Nagata, T. Sasaki, T. Mori et al., "Cisternal talc injection in dog can induce delayed and prolonged arterial constriction resembling cerebral vasospasm morphologically and pharmacologically," Surgical Neurology, vol. 45, no. 5, pp. 442-447, 1996.

[89] J. W. Peterson, B.-D. Kwun, J. D. Hackett, and N. T. Zervas, "The role of inflammation in experimental cerebral vasospasm," Journal of Neurosurgery, vol. 72, no. 5, pp. 767-774, 1990.

[90] H. Yanamoto, H. Kikuchi, S. Okamoto, and K. Nozaki, "Cerebral vasospasm caused by cisternal injection of polystyrene latex beads in rabbits is inhibited by a serine protease inhibitor," Surgical Neurology, vol. 42, no. 5, pp. 374-381, 1994.

[91] P. F. Recinos, G. Pradilla, Q.-A. Thai, M. Perez, A. M. Hdeib, and R. J. Tamargo, "Controlled release of lipopolysaccharide in the subarachnoid space of rabbits induces chronic vasospasm in the absence of blood," Surgical Neurology, vol. 66, no. 5, pp. 463-469, 2006

[92] M. Fujimoto, H. Suzuki, M. Shiba et al., "Tenascin-C induces prolonged constriction of cerebral arteries in rats," Neurobiology of Disease, vol. 55, pp. 104-109, 2013.

[93] S. Schmidt, M. Moser, and M. Sperandio, "The molecular basis of leukocyte recruitment and its deficiencies," Molecular Immunology, vol. 55, no. 1, pp. 49-58, 2013.

[94] J. J. Nissen, D. Mantle, B. Gregson, and A. D. Mendelow, "Serum concentration of adhesion molecules in patients with delayed ischaemic neurological deficit after aneurysmal subarachnoid haemorrhage: the immunoglobulin and selectin superfamilies," Journal of Neurology Neurosurgery and Psychiatry, vol. 71, no. 3, pp. 329-333, 2001.
[95] E. M. Oshiro, P. A. Hoffman, G. N. Dietsch, M. C. Watts, D. M. Pardoll, and R. J. Tamargo, "Inhibition of experimental vasospasm with anti-intercellular adhesion molecule-1 monoclonal antibody in rats," Stroke, vol. 28, no. 10, pp. 2031-2038, 1997.

[96] W. Ni, Y. X. Gu, D. L. Song, B. Leng, P. L. Li, and Y. Mao, "The relationship between IL-6 in CSF and occurrence of vasospasm after subarachnoid hemorrhage," Acta Neurochirurgica, Supplementum, no. 110, part 1, pp. 203-208, 2011.

[97] S. Hendryk, B. Jarzab, and J. Josko, "Increase of the IL-1 $\beta$ and IL6 levels in CSF in patients with vasospasm following aneurysmal SAH," Neuroendocrinology Letters, vol. 25, no. 1-2, pp. 141-147, 2004.

[98] D.-H. Nam, J.-S. Kim, S.-C. Hong et al., "Expression of interleukin $-1 \beta$ in lipopolysaccharide stimulated monocytes derived from patients with aneurysmal subarachnoid hemorrhage is correlated with cerebral vasospasm," Neuroscience Letters, vol. 312, no. 1, pp. 41-44, 2001.

[99] Y. Wang, M. Zhong, X.-X. Tan et al., "Expression change of interleukin-8 gene in rabbit basilar artery after subarachnoid hemorrhage," Neuroscience Bulletin, vol. 23, no. 3, pp. 151-155, 2007.

[100] C. Muroi, M. Seule, C. Sikorski, W. Dent, and E. Keller, "Systemic interleukin-6 levels reflect illness course and prognosis of patients with spontaneous nonaneurysmal subarachnoid hemorrhage," Acta Neurochirurgica, Supplementum, vol. 115, pp. 77-80, 2013.

[101] H. Lu, J.-X. Shi, H.-L. Chen, C.-H. Hang, H.-D. Wang, and H.-X. Yin, "Expression of monocyte chemoattractant protein-1 in the cerebral artery after experimental subarachnoid hemorrhage," Brain Research, vol. 1262, pp. 73-80, 2009.

[102] G. Bowman, S. Dixit, R. H. Bonneau et al., "Neutralizing antibody against interleukin-6 attenuates posthemorrhagic vasospasm in the rat femoral artery model," Neurosurgery, vol. 54, no. 3, pp. 719-726, 2004.

[103] C. Vecchione, A. Frati, A. di Pardo et al., "Tumor necrosis factor- $\alpha$ mediates hemolysis-induced vasoconstriction and the cerebral vasospasm evoked by subarachnoid hemorrhage," Hypertension, vol. 54, no. 1, pp. 150-156, 2009.

[104] J. S. C. Arthur and S. C. Ley, "Mitogen-activated protein kinases in innate immunity," Nature Reviews Immunology, vol. 13, no. 9, pp. 679-692, 2013.

[105] H. Yatsushige, M. Yamaguchi, C. Zhou, J. W. Calvert, and J. H. Zhang, "Role of c-Jun N-terminal kinase in cerebral vasospasm after experimental subarachnoid hemorrhage," Stroke, vol. 36, no. 7, pp. 1538-1543, 2005.

[106] H. Yatsushige, M. Yamaguchi-Okada, C. Zhou et al., "Inhibition of c-Jun N-terminal kinase pathway attenuates cerebral vasospasm after experimental subarachnoid hemorrhage through the suppression of apoptosis," Acta Neurochirurgica, Supplementum, vol. 104, pp. 27-31, 2008.

[107] S. Cuzzocrea, "Shock, inflammation and PARP," Pharmacological Research, vol. 52, no. 1, pp. 72-82, 2005.

[108] M. Satoh, I. Date, M. Nakajima et al., "Inhibition of poly(ADPribose) polymerase attenuates cerebral vasospasm after subarachnoid hemorrhage in rabbits," Stroke, vol. 32, no. 1, pp. 225231, 2001.

[109] J. W. German, C. E. Gross, P. Giclas, W. Watral, and M. M. Bednar, "Systemic complement depletion inhibits experimental cerebral vasospasm," Neurosurgery, vol. 39, no. 1, pp. 141-146, 1996. 
[110] H. Yanamoto, H. Kikuchi, S. Okamoto, and K. Nozaki, "Preventive effect of synthetic serine protease inhibitor, FUT-175, on cerebral vasospasm in rabbits," Neurosurgery, vol. 30, no. 3, pp. 351-357, 1992.

[111] M. Kaminogo, M. Yonekura, M. Onizuka, A. Yasunaga, and S. Shibata, "Combination of serine protease inhibitor FUT175 and thromboxane synthetase inhibitor OKY-046 decreases cerebral vasospasm in patients with subarachnoid hemorrhage," Neurologia Medico-Chirurgica, vol. 38, no. 11, pp. 704-709, 1998.

[112] H. Yanamoto, H. Kikuchi, M. Sato, Y. Shimizu, S. Yoneda, and S. Okamoto, "Therapeutic trial of cerebral vasospasm with the serine protease inhibitor, FUT-175, administered in the acute stage after subarachnoid hemorrhage," Neurosurgery, vol. 30, no. 3, pp. 358-363, 1992.

[113] C. Zhang, J.-Y. Lee, R. F. Keep et al., "Brain edema formation and complement activation in a rat model of subarachnoid hemorrhage," Acta neurochirurgica. Supplement, vol. 118, pp. 157-161, 2013.

[114] E. R. Zanier, R. Zangari, L. Munthe-Fog et al., "Ficolin-3mediated lectin complement pathway activation in patients with subarachnoid hemorrhage," Neurology, vol. 82, no. 2, pp. 126-134, 2014.

[115] H. L. Hsieh and C. M. Yang, "Role of redox signaling in neuroinflammation and neurodegenerative diseases," BioMed Research International, vol. 2013, Article ID 484613, 18 pages, 2013.

[116] J. M. C. Gutteridge, "The antioxidant activity of haptoglobin towards haemoglobin-stimulated lipid peroxidation," Biochimica et Biophysica Acta-Lipids and Lipid Metabolism, vol. 917, no. 2, pp. 219-223, 1987.

[117] H. J. Møller, N. A. Peterslund, J. H. Graversen, and S. K. Moestrup, "Identification of the hemoglobin scavenger receptor/CD163 as a natural soluble protein in plasma," Blood, vol. 99, no. 1, pp. 378-380, 2002.

[118] B. H. Bowman and A. Kurosky, "Haptoglobin: the evolutionary product of duplication, unequal crossing over, and point mutation," Advances in Human Genetics, vol. 12, pp. 189-454, 1982.

[119] M. Borsody, A. Burke, W. Coplin, R. Miller-Lotan, and A. Levy, "Haptoglobin and the development of cerebral artery vasospasm after subarachnoid hemorrhage," Neurology, vol. 66, no. 5, pp. 634-640, 2006.

[120] K. L. Chaichana, A. P. Levy, R. Miller-Lotan, S. Shakur, and R. J. Tamargo, "Haptoglobin 2-2 genotype determines chronic vasospasm after experimental subarachnoid hemorrhage," Stroke, vol. 38, no. 12, pp. 3266-3271, 2007.

[121] H. Ohnishi, K. Iihara, Y. Kaku et al., "Haptoglobin phenotype predicts cerebral vasospasm and clinical deterioration after aneurysmal subarachnoid hemorrhage," Journal of Stroke and Cerebrovascular Diseases, vol. 22, no. 4, pp. 520-526, 2013.

[122] E. Kantor, H. Bayir, D. Ren et al., "Haptoglobin genotype and functional outcome after aneurysmal subarachnoid hemorrhage," Journal of Neurosurgery, vol. 120, no. 2, pp. 386-390, 2014.

[123] J. P. Cooke and V. J. Dzau, "Nitric oxide synthase: role in the genesis of vascular disease," Annual Review of Medicine, vol. 48, pp. 489-509, 1997.

[124] E. E. van Faassen, S. Bahrami, M. Feelisch et al., "Nitrite as regulator of hypoxic signaling in mammalian physiology," Medicinal Research Reviews, vol. 29, no. 5, pp. 683-741, 2009.

[125] Y.-M. Yang, A. Huang, G. Kaley, and D. Sun, "eNOS uncoupling and endothelial dysfunction in aged vessels," American Journal of Physiology-Heart and Circulatory Physiology, vol. 297, no. 5, pp. H1829-H1836, 2009.

[126] G. Pradilla, T. Garzon-Muvdi, J. J. Ruzevick et al., "Systemic L-citrulline prevents cerebral vasospasm in haptoglobin 2-2 transgenic mice after subarachnoid hemorrhage," Neurosurgery, vol. 70, no. 3, pp. 747-757, 2012.

[127] M. Sabri, J. Ai, B. Knight et al., "Uncoupling of endothelial nitric oxide synthase after experimental subarachnoid hemorrhage," Journal of Cerebral Blood Flow and Metabolism, vol. 31, no. 1, pp. 190-199, 2011.

[128] M. Sabri, J. Ai, P. A. Marsden, and R. L. Macdonald, "Simvastatin re-couples dysfunctional endothelial nitric oxide synthase in experimental subarachnoid hemorrhage," PLoS ONE, vol. 6, no. 2, Article ID e17062, 2011.

[129] M. Sabri, J. Ai, E. Lass, J. D'Abbondanza, and R. L. MacDonald, "Genetic elimination of eNOS reduces secondary complications of experimental subarachnoid hemorrhage," Journal of Cerebral Blood Flow and Metabolism, vol. 33, no. 7, pp. 1008-1014, 2013.

[130] T. Miyauchi and T. Masaki, "Pathophysiology of endothelin in the cardiovascular system," Annual Review of Physiology, vol. 61, pp. 391-415, 1999.

[131] L. Mascia, L. Fedorko, D. J. Stewart et al., “Temporal relationship between endothelin-1 concentrations and cerebral vasospasm in patients with aneurysmal subarachnoid hemorrhage," Stroke, vol. 32, no. 5, pp. 1185-1189, 2001.

[132] I. Yamaura, E. Tani, Y. Maeda, N. Minami, and H. Shindo, "Endothelin-1 of canine basilar artery in vasospasm," Journal of Neurosurgery, vol. 76, no. 1, pp. 99-105, 1992.

[133] M. Zuccarello, R. Boccaletti, A. Romano, and R. M. Rapoport, "Endothelin B receptor antagonists attenuate subarachnoid hemorrhage-induced cerebral vasospasm," Stroke, vol. 29, no. 9, pp. 1924-1929, 1998.

[134] Y. Matsumura, R. Ikegawa, Y. Suzuki et al., "Phosphoramidon prevents cerebral vasospasm following subarachnoid hemorrhage in dogs: the relationship to endothelin-1 levels in the cerebrospinal fluid," Life Sciences, vol. 49, no. 11, pp. 841-848, 1991.

[135] J. Konczalla, J. Mrosek, S. Wanderer et al., "Functional effects of levosimendan in rat basilar arteries in vitro," Current Neurovascular Research, vol. 10, no. 2, pp. 126-133, 2013.

[136] F. Cosentino, E. G. McMahon, J. S. Carter, and Z. S. Katusic, "Effect of endothelin(A)-receptor antagonist BQ-123 and phosphoramidon on cerebral vasospasm," Journal of Cardiovascular Pharmacology, vol. 22, supplement 8, pp. S332-S335, 1993.

[137] P. K. Yeung, J. Shen, S. S. Chung, and S. K. Chung, “Targeted over-expression of endothelin-1 in astrocytes leads to more severe brain damage and vasospasm after subarachnoid hemorrhage," BMC Neuroscience, vol. 14, no. 1, p. 131, 2013.

[138] J. M. Findlay, B. K. A. Weir, D. Steinke, T. Tanabe, P. Gordon, and M. Grace, "Effect of intrathecal thrombolytic therapy on subarachnoid clot and chronic vasospasm in a primate model of SAH," Journal of Neurosurgery, vol. 69, no. 5, pp. 723-735, 1988.

[139] J. M. Findlay, N. F. Kassell, B. K. A. Weir et al., "A randomized trial of intraoperative, intracisternal tissue plasminogen activator for the prevention of vasospasm," Neurosurgery, vol. 37, no. 1, pp. $168-178,1995$.

[140] Y. Kai, K. Ito, M. Watanabe et al., "Development of a kit to treat subarachnoid hemorrhage by intrathecal simple urokinase infusion (ITSUKI) therapy: preliminary results in patients with World Federation of Neurological Surgery (WFNS) Grade v subarachnoid hemorrhage," World Neurosurgery, vol. 75, no. 34, pp. 485-490, 2011. 
[141] J.-I. Hamada, Y. Kai, M. Morioka et al., "Effect on cerebral vasospasm of coil embolization followed by microcatheter intrathecal urokinase infusion into the cisterna magna: a prospective randomized study," Stroke, vol. 34, no. 11, pp. 25492554, 2003.

[142] T. Mizuno, J.-I. Hamada, Y. Kai, T. Todaka, M. Morioka, and Y. Ushio, "Intrathecal urokinase infusion through a microcatheter into the cisterna magna to prevent cerebral vasospasm: experimental study in dogs," American Journal of Neuroradiology, vol. 24, no. 4, pp. 613-618, 2003.

[143] J.-I. Hamada, T. Mizuno, Y. Kai, M. Morioka, and Y. Ushio, "Microcatheter intrathecal urokinase infusion into cisterna magna for prevention of cerebral vasospasm: preliminary report," Stroke, vol. 31, no. 9, pp. 2141-2148, 2000.

[144] S. Amin-Hanjani, C. S. Ogilvy, F. G. Barker II et al., "Does intracisternal thrombolysis prevent vasospasm after aneurysmal subarachnoid hemorrhage? A meta-analysis," Neurosurgery, vol. 54, no. 2, pp. 326-335, 2004.

[145] T. Yamamoto, T. Esaki, Y. Nakao, and K. Mori, "Efficacy of lowdose tissue-plasminogen activator intracisternal administration for the prevention of cerebral vasospasm after subarachnoid hemorrhage," World Neurosurgery, vol. 73, no. 6, pp. 675-682, 2010.

[146] J. H. Kim, H. J. Yi, Y. Ko, Y. S. Kim, D. W. Kim, and J. M. Kim, "Effectiveness of papaverine cisternal irrigation for cerebral vasospasm after aneurysmal subarachnoid hemorrhage and measurement of biomarkers," Neurological Sciences, vol. 35, no. 5, pp. 715-722, 2014.

[147] D. Chyatte and T. M. Sundt Jr., "Response of chronic experimental cerebral vasospasm to methylprednisolone and dexamethasone," Journal of Neurosurgery, vol. 60, no. 5, pp. 923-926, 1984.

[148] D. Chyatte, "Prevention of chronic cerebral vasospasm in dogs with ibuprofen and high-dose methylprednisolone," Stroke, vol. 20, no. 8, pp. 1021-1026, 1989.

[149] D. Chyatte, N. Rusch, and T. M. Sundt Jr., "Prevention of chronic experimental cerebral vasospasm with ibuprofen and high-dose methylprednisolone," Journal of Neurosurgery, vol. 59, no. 6, pp. 925-932, 1983.

[150] D. Chyatte, N. C. Fode, D. A. Nichols, and T. M. Sundt Jr., "Preliminary report: effects of high dose methylprednisolone on delayed cerebral ischemia in patients at high risk for vasospasm after aneurysmal subarachnoid hemorrhage," Neurosurgery, vol. 21, no. 2, pp. 157-160, 1987.

[151] K. Hashi, K. Takakura, K. Sano, T. Ohta, I. Saito, and K. Okada, "Intravenous hydrocortisone in large doses for the treatment of delayed ischemic neurological deficits following subarachnoid hemorrhage-results of a multi-center controlled double-blind clinical study," Brain and Nerve, vol. 40, no. 4, pp. 373-382, 1988.

[152] Y. Katayama, J. Haraoka, H. Hirabayashi et al., "A randomized controlled trial of hydrocortisone against hyponatremia in patients with aneurysmal subarachnoid hemorrhage," Stroke, vol. 38, no. 8, pp. 2373-2375, 2007.

[153] N. Moro, Y. Katayama, J. Kojima, T. Mori, and T. Kawamata, "Prophylactic management of excessive natriuresis with hydrocortisone for efficient hypervolemic therapy after subarachnoid hemorrhage," Stroke, vol. 34, no. 12, pp. 2807-2811, 2003.

[154] T. Mori, Y. Katayama, T. Kawamata, and T. Hirayama, "Improved efficiency of hypervolemic therapy with inhibition of natriuresis by fludrocortisone in patients with aneurysmal subarachnoid hemorrhage," Journal of Neurosurgery, vol. 91, no. 6, pp. 947-952, 1999.
[155] P. Gomis, J. P. Graftieaux, R. Sercombe, D. Hettler, B. Scherpereel, and P. Rousseaux, "Randomized, double-blind, placebo-controlled, pilot trial of high-dose methylprednisolone in aneurysmal subarachnoid hemorrhage," Journal of Neurosurgery, vol. 112, no. 3, pp. 681-688, 2010.

[156] G. A. Green, "Understanding NSAIDs: from aspirin to COX-2," Clinical Cornerstone, vol. 3, no. 5, pp. 50-59, 2001.

[157] R. P. White and J. T. Robertson, "Comparison of piroxicam, meclofenamate, ibuprofen, aspirin, and prostacyclin efficacy in a chronic model of cerebral vasospasm," Neurosurgery, vol. 12, no. 1, pp. 40-46, 1983.

[158] G. Pradilla, Q.-A. Thai, F. G. Legnani et al., "Local delivery of ibuprofen via controlled-release polymers prevents angiographic vasospasm in a monkey model of subarachnoid hemorrhage," Neurosurgery, vol. 57, no. 1, pp. S-184-S-190, 2005.

[159] Q.-A. Thai, E. M. Oshiro, and R. J. Tamargo, "Inhibition of experimental vasospasm in rats with the periadventitial administration of ibuprofen using controlled-release polymers," Stroke, vol. 30, no. 1, pp. 140-147, 1999.

[160] J. L. Frazier, G. Pradilla, P. P. Wang, and R. J. Tamargo, "Inhibition of cerebral vasospasm by intracranial delivery of ibuprofen from a controlled-release polymer in a rabbit model of subarachnoid hemorrhage," Journal of Neurosurgery, vol. 101, no. 1, pp. 93-98, 2004.

[161] Ö. Çelik, B. Bilginer, A. Korkmaz et al., "Effects of intramuscular parecoxib administration on vasospasm in an experimental subarachnoid hemorrhage model," International Journal of Neuroscience, vol. 121, no. 6, pp. 316-322, 2011.

[162] B. K. Mani, L. I. Brueggemann, L. L. Cribbs, and K. L. Byron, "Activation of vascular KCNQ (Kv7) potassium channels reverses spasmogen-induced constrictor responses in rat basilar artery," British Journal of Pharmacology, vol. 164, no. 2, pp. 237249, 2011.

[163] B. K. Mani, J. O'Dowd, L. Kumar, L. I. Brueggemann, M. Ross, and K. L. Byron, "Vascular KCNQ (Kv7) potassium channels as common signaling intermediates and therapeutic targets in cerebral vasospasm," Journal of Cardiovascular Pharmacology, vol. 61, no. 1, pp. 51-62, 2013.

[164] D. I. Pritchard, "Sourcing a chemical succession for cyclosporin from parasites and human pathogens," Drug Discovery Today, vol. 10, no. 10, pp. 688-691, 2005.

[165] Y. Handa, M. Hayashi, H. Takeuchi, H. Kobayashi, H. Kawano, and M. Kabuto, "Effect of cyclosporine on the development of cerebral vasospasm in a primate model," Neurosurgery, vol. 28, no. 3, pp. 380-386, 1991.

[166] J. W. Peterson, S. Nishizawa, J. D. Hackett, T. Bun, A. Teramura, and N. T. Zervas, "Cyclosporine A reduces cerebral vasospasm after subarachnoid hemorrhage in dogs," Stroke, vol. 21, no. 1, pp. 133-137, 1990.

[167] E. M. Manno, D. R. Gress, C. S. Ogilvy, C. M. Stone, and N. T. Zervas, "The safety and efficacy of cyclosporine A in the prevention of vasospasm in patients with Fisher Grade 3 subarachnoid hemorrhages: a pilot study," Neurosurgery, vol. 40, no. 2, pp. 289-293, 1997.

[168] M. Ryba, M. Pastuszko, K. Iwanska, J. Bidzinski, and C. Dziewiecki, "Cyclosporine A prevents neurological deterioration of patients with SAH-a preliminary report," Acta Neurochirurgica, vol. 112, no. 1-2, pp. 25-27, 1991.

[169] M. Ryba, M. Pastuszko, C. Dziewiecki, J. Andrychowski, P. Bojarski, and M. Barczewska, "A strategy for analyzing multiple parameters with application to aneurysmal SAH patients all of 
them clipped but treated with and without cyclosporine," Acta Neurochirurgica, vol. 122, no. 3-4, pp. 194-199, 1993.

[170] M. Ryba, P. Grieb, J. Bidzinski, M. Pastuszko, C. Dziewiecki, and $\mathrm{K}$. Iwanska, "Cyclosporine A for the prevention of neurological deficit following subarachnoid hemorrhage," Stroke, vol. 22, no. 4, p. 531, 1991.

[171] T. Mori, K. Nagata, T. Ishida et al., "FK-506: a new immunosuppressive agent, failed to reduce cerebral vasospasm after experimental subarachnoid hemorrhage," The Journal of Veterinary Medical Science, vol. 55, no. 4, pp. 581-586, 1993.

[172] K. Nagata, T. Sasaki, J. Iwama et al., "Failure of FK-506, a new immunosuppressant, to prevent cerebral vasospasm in a canine two-hemorrhage model," Journal of Neurosurgery, vol. 79, no. 5, pp. 710-715, 1993.

[173] S. Nishizawa, J. W. Peterson, I. Shimoyama et al., "Therapeutic effect of a new immunosuppressant, FK-506, on vasospasm after subarachnoid hemorrhage," Neurosurgery, vol. 32, no. 6, pp. 986-992, 1993.

[174] E. Ascer, M. C. Bertolami, M. L. Venturinelli et al., "Atorvastatin reduces proinflammatory markers in hypercholesterolemic patients," Atherosclerosis, vol. 177, no. 1, pp. 161-166, 2004.

[175] M. Chello, M. Carassiti, F. Agrò et al., "Simvastatin blunts the increase of circulating adhesion molecules after coronary artery bypass surgery with cardiopulmonary bypass," Journal of Cardiothoracic and Vascular Anesthesia, vol. 18, no. 5, pp. 605609, 2004.

[176] C.-Z. Chang, S.-C. Wu, C.-L. Lin, S.-L. Hwang, S.-L. Howng, and A.-L. Kwan, "Atorvastatin preconditioning attenuates the production of endothelin-1 and prevents experimental vasospasm in rats," Acta Neurochirurgica, vol. 152, no. 8, pp. 1399-1405, 2010.

[177] M. J. McGirt, J. R. Lynch, A. Parra et al., "Simvastatin increases endothelial nitric oxide synthase and ameliorates cerebral vasospasm resulting from subarachnoid hemorrhage," Stroke, vol. 33, no. 12, pp. 2950-2956, 2002.

[178] Y.-C. Doo, S.-J. Han, S.-W. Han et al., "Effect of preexisting statin use on expression of C-reactive protein, adhesion molecules, interleukin-6, and antioxidized low-density lipoprotein antibody in patients with unstable angina undergoing coronary stenting," Clinical Cardiology, vol. 28, no. 2, pp. 72-76, 2005.

[179] K. K. Koh, J. W. Son, J. Y. Ahn et al., "Vascular effects of diet and statin in hypercholesterolemic patients," International Journal of Cardiology, vol. 95, no. 2-3, pp. 185-191, 2004.

[180] A. Rezaie-Majd, G. W. Prager, R. A. Bucek et al., "Simvastatin reduces the expression of adhesion molecules in circulating monocytes from hypercholesterolemic patients," Arteriosclerosis, Thrombosis, and Vascular Biology, vol. 23, no. 3, pp. 397-403, 2003.

[181] A. Parra, K. T. Kreiter, S. Williams et al., "Effect of prior statin use on functional outcome and delayed vasospasm after acute aneurysmal subarachnoid hemorrhage: a matched controlled cohort study," Neurosurgery, vol. 56, no. 3, pp. 476-484, 2005.

[182] A. H. Kramer, M. J. Gurka, B. Nathan, A. S. Dumont, N. F. Kassell, and T. P. Bleck, "Statin use was not associated with less vasospasm or improved outcome after subarachnoid hemorrhage," Neurosurgery, vol. 62, no. 2, pp. 422-427, 2008.

[183] M. J. McGirt, G. L. Garces Ambrossi, J. Huang, and R. J. Tamargo, "Simvastatin for the prevention of symptomatic cerebral vasospasm following aneurysmal subarachnoid hemorrhage: a single-institution prospective cohort study: clinical article," Journal of Neurosurgery, vol. 110, no. 5, pp. 968-974, 2009.
[184] P. Sanchez-Peña, A. Nouet, F. Clarençon et al., "Atorvastatin decreases computed tomography and S100-assessed brain ischemia after subarachnoid aneurysmal hemorrhage: a comparative study," Critical Care Medicine, vol. 40, no. 2, pp. 594602, 2012.

[185] M.-Y. Tseng, M. Czosnyka, H. Richards, J. D. Pickard, and P. J. Kirkpatrick, "Effects of acute treatment with pravastatin on cerebral vasospasm, autoregulation, and delayed ischemic deficits after aneurysmal subarachnoid hemorrhage: a phase II randomized placebo-controlled trial," Stroke, vol. 36, no. 8, pp. $1627-1632,2005$.

[186] M.-Y. Tseng, P. J. Hutchinson, M. Czosnyka, H. Richards, J. D. Pickard, and P. J. Kirkpatrick, "Effects of acute pravastatin treatment on intensity of rescue therapy, length of inpatient stay, and 6-month outcome in patients after aneurysmal subarachnoid hemorrhage," Stroke, vol. 38, no. 5, pp. 1545-1550, 2007.

[187] Z. Liu, L. Liu, Z. Zhang, Z. Chen, and B. Zhao, "Cholesterolreducing agents for aneurysmal subarachnoid haemorrhage," The Cochrane Database of Systematic Reviews, vol. 4, Article ID CD008184, 2013.

[188] R. M. Pluta, "Delayed cerebral vasospasm and nitric oxide: review, new hypothesis, and proposed treatment," Pharmacology and Therapeutics, vol. 105, no. 1, pp. 23-56, 2005.

[189] R. M. Pluta, A. Dejam, G. Grimes, M. T. Gladwin, and E. H. Oldfield, "Nitrite infusions to prevent delayed cerebral vasospasm in a primate model of subarachnoid hemorrhage," Journal of the American Medical Association, vol. 293, no. 12, pp. 1477-1484, 2005.

[190] P. Gabikian, R. E. Clatterbuck, C. G. Eberhart, B. M. Tyler, T. S. Tierney, and R. J. Tamargo, "Prevention of experimental cerebral vasospasm by intracranial delivery of a nitric oxide donor from a controlled-release polymer: toxicity and efficacy studies in rabbits and rats," Stroke, vol. 33, no. 11, pp. 2681-2686, 2002.

[191] G. Pradilla, Q.-A. Thai, F. G. Legnani et al., "Delayed intracranial delivery of a nitric oxide donor from a controlled-release polymer prevents experimental cerebral vasospasm in rabbits," Neurosurgery, vol. 55, no. 6, pp. 1393-1400, 2004.

[192] R. M. Pluta, E. H. Oldfield, and R. J. Boock, "Reversal and prevention of cerebral vasospasm by intracarotid infusions of nitric oxide donors in a primate model of subarachnoid hemorrhage," Journal of Neurosurgery, vol. 87, no. 5, pp. 746751, 1997.

[193] N. Egemen, R. K. Turker, U. Sanlidilek et al., "The effect of intrathecal sodium nitroprusside on severe chronic vasospasm," Neurological Research, vol. 15, no. 5, pp. 310-315, 1993.

[194] A. R. Fathi, R. M. Pluta, K. D. Bakhtian, M. Qi, and R. R. Lonser, "Reversal of cerebral vasospasm via intravenous sodium nitrite after subarachnoid hemorrhage in primates: laboratory investigation," Journal of Neurosurgery, vol. 115, no. 6, pp. 12131220, 2011.

[195] L. P. Solomonson, B. R. Flam, L. C. Pendleton, B. L. Goodwin, and D. C. Eichler, "The caveolar nitric oxide synthase/arginine regeneration system for NO production in endothelial cells," The Journal of Experimental Biology, vol. 206, no. 12, pp. 20832087, 2003

[196] P. Kubes, M. Suzuki, and D. N. Granger, "Nitric oxide: an endogenous modulator of leukocyte adhesion," Proceedings of the National Academy of Sciences of the United States of America, vol. 88, no. 11, pp. 4651-4655, 1991.

[197] M. Suematsu, T. Tamatani, F. A. Delano et al., "Microvascular oxidative stress preceding leukocyte activation elicited by in 
vivo nitric oxide suppression," American Journal of PhysiologyHeart and Circulatory Physiology, vol. 266, no. 6, pp. H2410H2415, 1994.

[198] I. Kurose, P. Kubes, R. Wolf et al., "Inhibition of nitric oxide production: mechanisms of vascular albumin leakage," Circulation Research, vol. 73, no. 1, pp. 164-171, 1993.

[199] P. Kubes and D. N. Granger, "Nitric oxide modulates microvascular permeability," American Journal of Physiology-Heart and Circulatory Physiology, vol. 262, no. 2, pp. H611-H615, 1992.

[200] J. Gaboury, R. C. Woodman, D. N. Granger, P. Reinhardt, and P. Kubes, "Nitric oxide prevents leukocyte adherence: role of superoxide," American Journal of Physiology-Heart and Circulatory Physiology, vol. 265, no. 3, part 2, pp. H862-H867, 1993.

[201] R. L. Macdonald, "Delayed neurological deterioration after subarachnoid haemorrhage," Nature Reviews: Neurology, vol. 10, no. 1, pp. 44-58, 2014.

[202] G. Chen, A. Tariq, J. Ai et al., "Different effects of clazosentan on consequences of subarachnoid hemorrhage in rats," Brain Research, vol. 1392, pp. 132-139, 2011.

[203] R. L. MacDonald, N. F. Kassell, S. Mayer et al., "Clazosentan to overcome neurological ischemia and infarction occurring after subarachnoid hemorrhage (CONSCIOUS-1): randomized, double-blind, placebo-controlled phase 2 dose-finding trial," Stroke, vol. 39, no. 11, pp. 3015-3021, 2008.

[204] M. D. I. Vergouwen, A. Algra, and G. J. E. Rinkel, "Endothelin receptor antagonists for aneurysmal subarachnoid hemorrhage: a systematic review and meta-analysis update," Stroke, vol. 43, no. 10, pp. 2671-2676, 2012.

[205] J. Kambayashi, Y. Liu, B. Sun, Y. Shakur, M. Yoshitake, and F. Czerwiec, "Cilostazol as a unique antithrombotic agent," Current Pharmaceutical Design, vol. 9, no. 28, pp. 2289-2302, 2003.

[206] W.-K. Jung, D.-Y. Lee, C. Park et al., "Cilostazol is antiinflammatory in BV2 microglial cells by inactivating nuclear factor-kappaB and inhibiting mitogen-activated protein kinases," British Journal of Pharmacology, vol. 159, no. 6, pp. 1274-1285, 2010.

[207] H. Ito, M. Fukunaga, H. Suzuki et al., "Effect of cilostazol on delayed cerebral vasospasm after subarachnoid hemorrhage in rats: evaluation using black blood magnetic resonance imaging," Neurobiology of Disease, vol. 32, no. 1, pp. 157-161, 2008.

[208] M. Yamaguchi-Okada, S. Nishizawa, A. Mizutani, and H. Namba, "Multifaceted effects of selective inhibitor of phosphodiesterase III, cilostazol, for cerebral vasospasm after subarachnoid hemorrhage in a dog model," Cerebrovascular Diseases, vol. 28, no. 2, pp. 135-142, 2009.

[209] T. Yoshimoto, T. Shirasaka, S. Fujimoto et al., "Cilostazol may prevent cerebral vasospasm following subarachnoid hemorrhage," Neurologia Medico-Chirurgica, vol. 49, no. 6, pp. 235241, 2009.

[210] T. Murahashi, K. Kamiyama, K. Hara et al., "The efficiency of cilostazol for cerebral vasospasm following subarachnoid hemorrhage," Neurological Surgery, vol. 41, no. 5, pp. 393-400, 2013.

[211] N. Senbokuya, H. Kinouchi, K. Kanemaru et al., "Effects of cilostazol on cerebral vasospasm after aneurysmal subarachnoid hemorrhage: a multicenter prospective, randomized, open-label blinded end point trial-clinical article," Journal of Neurosurgery, vol. 118, no. 1, pp. 121-130, 2013.

[212] R. Shechter and M. Schwartz, "Harnessing monocyte-derived macrophages to control central nervous system pathologies: no longer if but how',' Journal of Pathology, vol. 229, no. 2, pp. 332346, 2013.

[213] J. M. Gidday, Y. G. Gasche, J.-C. Copin et al., "Leukocytederived matrix metalloproteinase- 9 mediates blood-brain barrier breakdown and is proinflammatory after transient focal cerebral ischemia," American Journal of Physiology-Heart and Circulatory Physiology, vol. 289, no. 2, pp. H558-H568, 2005.

[214] M. Yepes and J. A. Winkles, "Inhibition of TWEAK activity as a new treatment for inflammatory and degenerative diseases," Drug News and Perspectives, vol. 19, no. 10, pp. 589-595, 2006.

[215] X. Zhang, J. A. Winkles, M. C. Gongora et al., “TWEAK-Fn14 pathway inhibition protects the integrity of the neurovascular unit during cerebral ischemia," Journal of Cerebral Blood Flow and Metabolism, vol. 27, no. 3, pp. 534-544, 2007.

[216] M. Katan and M. S. Elkind, "Inflammatory and neuroendocrine biomarkers of prognosis after ischemic stroke," Expert Review of Neurotherapeutics, vol. 11, no. 2, pp. 225-239, 2011.

[217] R. P. Ostrowski, A. R. Colohan, and J. H. Zhang, "Molecular mechanisms of early brain injury after subarachnoid hemorrhage," Neurological Research, vol. 28, no. 4, pp. 399-414, 2006.

[218] R. L. Macdonald, "Delayed neurological deterioration after subarachnoid haemorrhage," Nature Reviews Neurology, vol. 10, no. 1, pp. 44-58, 2014.

[219] B. Caner, J. Hou, O. Altay, M. Fuj II, and J. H. Zhang, "Transition of research focus from vasospasm to early brain injury after subarachnoid hemorrhage," Journal of Neurochemistry, vol. 123, supplement 2, pp. 12-21, 2012.

[220] S. M. Dorhout Mees, G. J. Rinkel, V. L. Feigin et al., "Calcium antagonists for aneurysmal subarachnoid haemorrhage," Cochrane Database of Systematic Reviews, no. 3, Article ID CD000277, 2007.

[221] V. L. Feigin, G. J. E. Rinkel, A. Algra, M. Vermeulen, and J. van Gijn, "Calcium antagonists in patients with aneurysmal subarachnoid hemorrhage: a systematic review," Neurology, vol. 50, no. 4, pp. 876-883, 1998.

[222] R. L. Macdonald, "Delayed neurological deterioration after subarachnoid haemorrhage," Nature Reviews Neurology, vol. 10, no. 1, pp. 44-58, 2014.

[223] M. D. I. Vergouwen, M. Vermeulen, J. van Gijn et al., "Definition of delayed cerebral ischemia after aneurysmal subarachnoid hemorrhage as an outcome event in clinical trials and observational studies: proposal of a multidisciplinary research group," Stroke, vol. 41, no. 10, pp. 2391-2395, 2010.

[224] V. L. Feigin, N. Anderson, G. J. Rinkel, A. Algra, J. van Gijn, and D. A. Bennett, "Corticosteroids for aneurysmal subarachnoid haemorrhage and primary intracerebral haemorrhage," Cochrane Database of Systematic Reviews, no. 3, Article ID CD004583, 2005.

[225] H. Yatsushige, R. P. Ostrowski, T. Tsubokawa, A. Colohan, and J. H. Zhang, "Role of c-Jun N-terminal kinase in early brain injury after subarachnoid hemorrhage," Journal of Neuroscience Research, vol. 85, no. 7, pp. 1436-1448, 2007.

[226] P. Bendel, T. Koivisto, T. Hänninen et al., "Subarachnoid hemorrhage is followed by temporomesial volume loss: MRI volumetric study," Neurology, vol. 67, no. 4, pp. 575-582, 2006.

[227] A. Petzold, G. Keir, A. Kay, M. Kerr, and E. J. Thompson, "Axonal damage and outcome in subarachnoid haemorrhage," Journal of Neurology, Neurosurgery and Psychiatry, vol. 77, no. 6, pp. 753759, 2006.

[228] S. P. Lad, H. Hegen, G. Gupta, F. Deisenhammer, and G. K. Steinberg, "Proteomic biomarker discovery in cerebrospinal 
fluid for cerebral vasospasm following subarachnoid hemorrhage," Journal of Stroke and Cerebrovascular Diseases, vol. 21, no. 1, pp. 30-41, 2012.

[229] Y. M. Ruigrok, A. J. C. Slooter, A. Bardoel, C. J. M. Frijns, G. J. E. Rinkel, and C. Wijmenga, "Genes and outcome after aneurysmal subarachnoid haemorrhage," Journal of Neurology, vol. 252, no. 4, pp. 417-422, 2005.

[230] D. J. Donnelly and P. G. Popovich, "Inflammation and its role in neuroprotection, axonal regeneration and functional recovery after spinal cord injury," Experimental Neurology, vol. 209, no. 2, pp. 378-388, 2008.

[231] B. L. Hoh, K. Hosaka, D. P. Downes et al., "Monocyte chemotactic protein-1 promotes inflammatory vascular repair of murine carotid aneurysms via a macrophage inflammatory protein- $1 \alpha$ and macrophage inflammatory protein-2-dependent pathway," Circulation, vol. 124, no. 20, pp. 2243-2252, 2011.

[232] K. A. Steer, T. M. Wallace, C. H. Bolton, and M. Hartog, "Aspirin protects low density lipoprotein from oxidative modification," Heart, vol. 77, no. 4, pp. 333-337, 1997.

[233] N. Ferri and A. Corsini, "Clinical evidence of statin therapy in non-dyslipidemic disorders," Pharmacological Research, 2014.

[234] S. Smithason, S. K. Moore, and J. J. Provencio, "Low-dose lipopolysaccharide injection prior to subarachnoid hemorrhage modulates delayed deterioration associated with vasospasm in subarachnoid hemorrhage," Acta Neurochirurgica, Supplementum, no. 115, pp. 253-258, 2013.

[235] Y. W. Kim, G. J. Zipfel, C. S. Ogilvy et al., "Preconditioning effect on cerebral vasospasm in patients with aneurysmal subarachnoid hemorrhage," Neurosurgery, vol. 74, no. 4, pp. 351359, 2014.

[236] I. E. Konstantinov, S. Arab, R. K. Kharbanda et al., "The remote ischemic preconditioning stimulus modifies inflammatory gene expression in humans," Physiological Genomics, vol. 19, pp. 143150, 2005. 


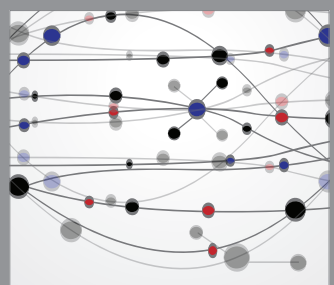

The Scientific World Journal
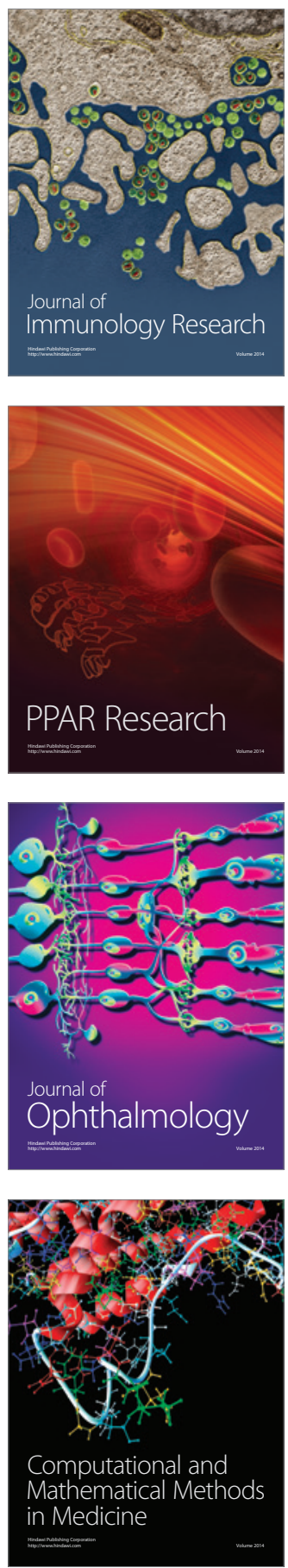

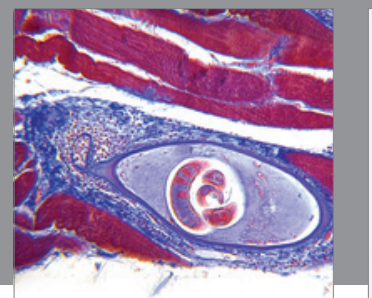

Gastroenterology

Research and Practice
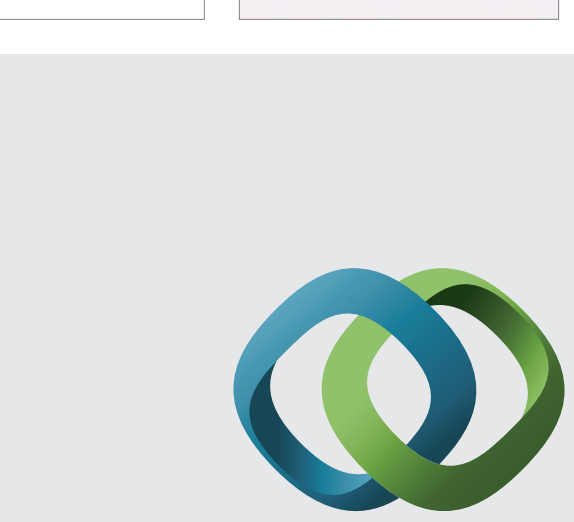

\section{Hindawi}

Submit your manuscripts at

http://www.hindawi.com
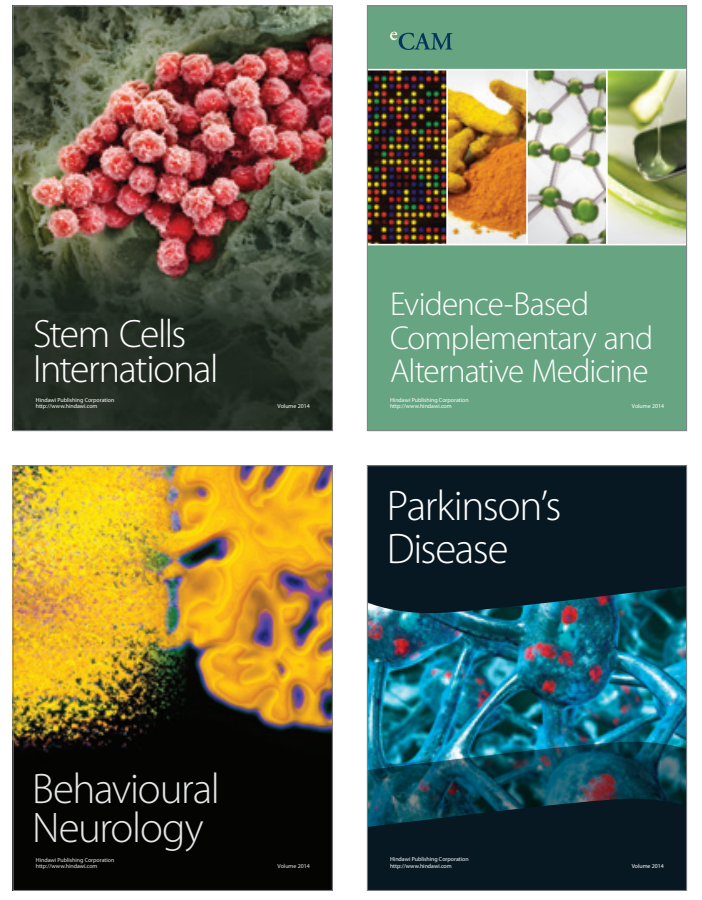
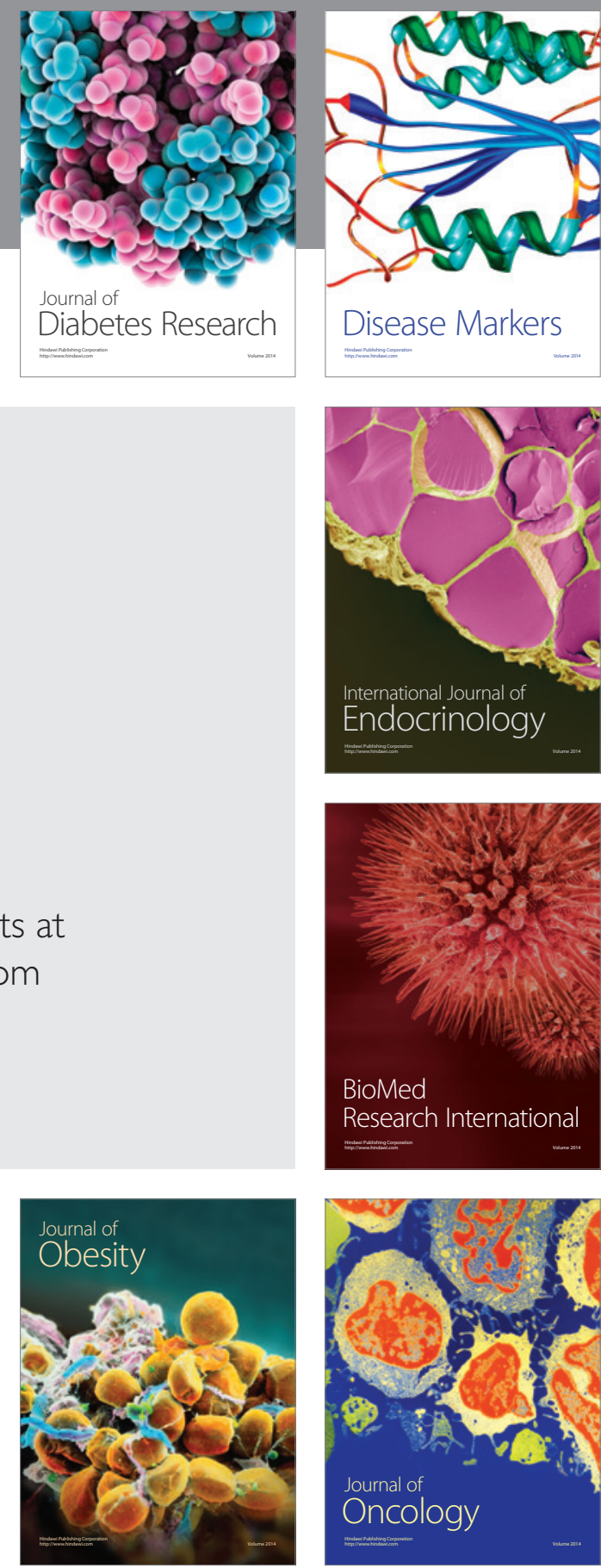

Disease Markers
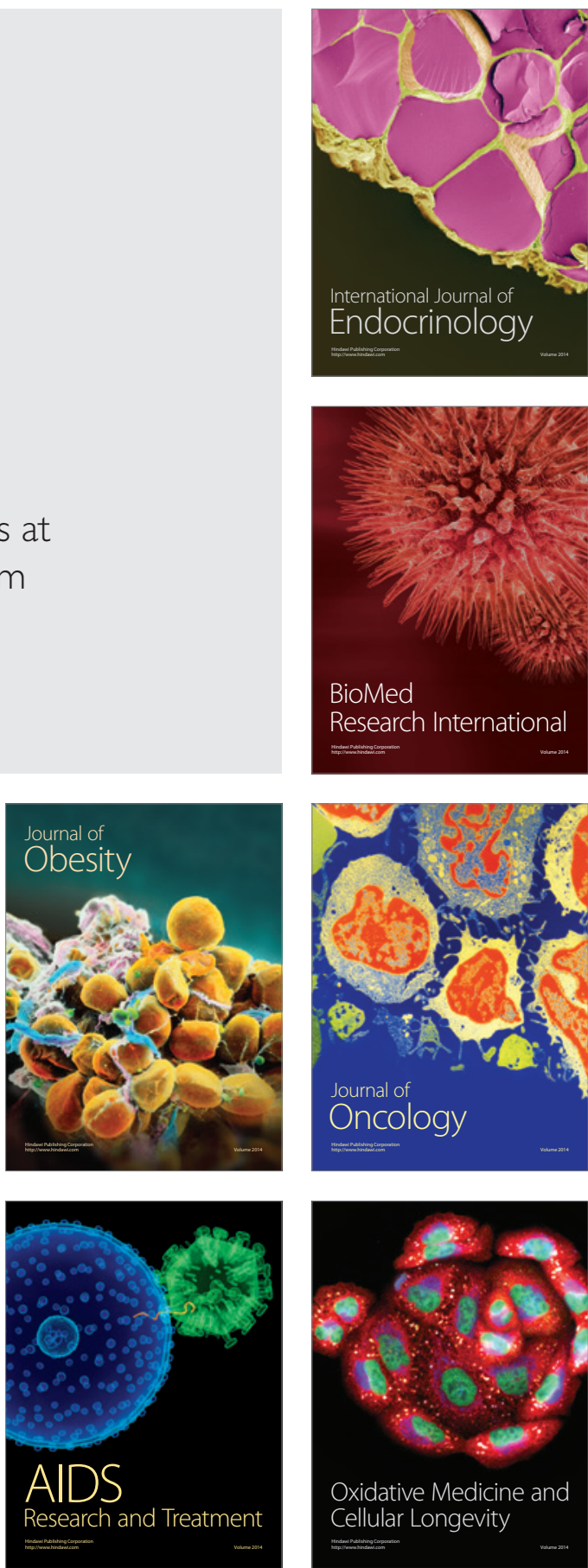